\title{
Turbulent Erosion of Persistent Cold-Air Pools: Numerical Simulations*
}

\author{
NeIL P. LAREAU AND JOHN D. HOREL \\ Department of Atmospheric Sciences, University of Utah, Salt Lake City, Utah
}

(Manuscript received 23 June 2014, in final form 10 October 2014)

\begin{abstract}
High-resolution idealized numerical simulations are used to examine the turbulent removal of cold-air pools commonly observed in mountain valleys and basins. A control simulation with winds aloft increasing from 0.5 to $20 \mathrm{~m} \mathrm{~s}^{-1}$ over $20 \mathrm{~h}$ combined with typical cold-air pool stratification illustrates the interplay over time of lowering of the top of the cold-air pool, spillover downstream of the valley from the upper reaches of the cold-air pool, wavelike undulations affecting the cold-air pool's depth and stratification across the valley, and smaller temporal- and spatial-scale Kelvin-Helmholtz waves within the uppermost layers of the cold-air pool. The heat budget within the cold-air pool demonstrates the nearly compensating effects of vertical and horizontal advection combined with turbulent heating of the upper portion of the cold-air pool and cooling in the layers immediately above the cold-air pool. Sensitivities of turbulent mixing in cold-air pools to stratification and upstream terrain are examined. Although the characteristics of the turbulent mixing differ as the stratification and topography are modified, a bulk parameter [the cold-air pool Froude number (Fr)] characterizes the onset and amplification of turbulent mixing and the time of cold-air pool removal. When $\mathrm{Fr}>1$, Kelvin-Helmholtz waves and turbulent heat fluxes commence. Turbulent heat flux and wave activity increase until Fr $=2$, after which the cold-air pool breaks down and is removed from the valley. The rate of cold-air pool removal is proportional to its strength; that is, a strong inversion generates larger heat fluxes once turbulent erosion is underway.
\end{abstract}

\section{Introduction}

Multiday cold-air pools (CAPs) are increasingly leading to hazardous levels of air pollution in both urban and rural mountain valleys (Reddy et al. 1995; Pataki et al. 2005, 2006; Malek et al. 2006; Schnell et al. 2009; Lareau et al. 2013). Since CAPs are characterized by stable stratification and limited mixing, greater accumulation of anthropogenic and biogenic aerosol result from longer-lived CAPs (Silcox et al. 2012). The resulting high concentrations of fine particulates, $\mathrm{PM}_{2.5}$, have been linked to increased risk for cardiovascular diseases, greater numbers of emergency room visits for asthma, and decreased lifespan (Pope et al. 2009; Beard et al. 2012).

\footnotetext{
* Supplemental information related to this paper is available at the Journals Online website: http://dx.doi.org/10.1175/JAS-D-14-0173.s1.

Corresponding author address: Neil Lareau, Department of Meteorology and Climate Sciences, San Jose State University, One Washington Square, San Jose, CA 95192-0104.

E-mail: neil.lareau@sjsu.edu
}

CAPs generally form during the onset of regional-scale high pressure systems when warming aloft couples with nocturnal radiative cooling to generate a deep stable layer (Wolyn and McKee 1989). The intensity and longevity of the CAP is modulated by variations in the surface energy budget and interactions between the CAP and passing weather systems (Wolyn and McKee 1989; Whiteman et al. 1999, 2001; Zhong et al. 2001; Reeves and Stensrud 2009; Gillies et al. 2010; Zardi and Whiteman 2013). The breakup of CAPs is most often due to vigorous cold-air advection associated with the passage of baroclinic troughs and fronts (Whiteman et al. 1999; Reeves and Stensrud 2009). However, in the absence of strong cold-air advection, CAP removal depends on the interplay between the CAP's stratification and the strength of winds aloft penetrating into the valley or basin (Lee et al. 1989; Petkovšek 1992; Petkovšek and Vrhovec 1994; Gubser and Richner 2001; Zängl 2003, 2005; Flamant et al. 2006; Lareau and Horel 2015). The downward penetration of strong winds can lead to displacement of the CAP as well as turbulent erosion of its stratification.

CAP displacement occurs because of regional pressure gradients and strong winds affecting valley stratification. 
For example, Petkovšek and Vrhovec (1994), and later Zängl (2003), demonstrated that CAPs develop a sloping upper surface toward the valley's downwind sidewalls wherein the depth of cold air deepens toward lower pressure. If the resulting CAP slope becomes sufficiently large, cold air is advected over the confining topography and the volume of air within the CAP is reduced (Zängl 2003, 2005). This tilt may also cause the CAP to contract from one end of the valley or basin, providing localized ventilation. CAP displacement is further influenced by wind stress and ageostrophic advection, both of which may increase the CAP slope and accelerate removal (Petkovšek and Vrhovec 1994; Gubser and Richner 2001; Zängl 2003, 2005; Lareau and Horel 2015).

Terrain-flow interaction may also displace a CAP. For example, Lee et al. (1989) find from numerical simulations that an inversion layer downwind of a mountain can be displaced by a mountain wave forming in cross-barrier flow. Observations further support that mountain waves occasionally remove CAPs, sometimes forming a warm front that sweeps through a valley (Whiteman et al. 2001; Flamant et al. 2006; Lareau and Horel 2015). Zängl (2005) demonstrates that such topographic influences on CAPs are sensitive to both wind direction and local topographic details.

The tendency for flow to sweep over the flanking topography and flush stratified air from a valley has been related to critical thresholds of a Froude number defined as

$$
F=\frac{U}{N H},
$$

where $U$ is the mean wind above the valley, $N$ is the Brunt-Väisälä frequency, and $H$ is the valley depth (Bell and Thompson 1980; Tampieri and Hunt 1985; Soontiens et al. 2013). Using idealized tank experiments, Bell and Thompson (1980) demonstrate that when $F \geq 1.2$, flow ventilates a valley regardless of the stratification. Grainger and Meroney (1993) find similar Froude number dependence for dispersion from an open-cut coalmine in stratified flow.

Terrain geometry and scale also affects the degree of valley ventilation and sheltering (Tampieri and Hunt 1985; Lee et al. 1987; Zängl 2005; Vosper and Brown 2008; Sheridan et al. 2014). For example, Vosper and Brown (2008) found that flow decoupling and cold-pool formation are sensitive to valley depth for an idealized narrow $(1 \mathrm{~km})$ valley. This relationship was expressed in terms of the nondimensional valley depth, which is the inverse of the Froude number. Recent observations in a narrow valley system support these findings (Sheridan et al. 2014). The dependence of CAP formation and removal on valley scale and aspect ratio is the topic of ongoing research (Sheridan and Vosper 2014). One complication among these and other studies is the specification of the values of $N$ and $H$ in the Froude number, which can strongly affect the interpretation of terrain-flow interactions (Reinecke and Durran 2008).

Strong winds aloft can also cause CAP removal by turbulent erosion, which is the downward progression of a less-dense layer into a stratified layer by turbulent entrainment across the interface (Kato and Phillips 1969; Pollard et al. 1973; Strang and Fernando 2001a,b). Laboratory tank experiments show that the entrainment is due to either dynamic instability, such as Kelvin-Helmholtz instability, or ambient turbulence in the layer aloft (Price et al. 1978). The rate of entrainment is governed by the Richardson number, which is the ratio of buoyant consumption to mechanical production of turbulent kinetic energy.

A key aspect of turbulent erosion is the increase in interfacial buoyancy gradient as the mixed layer aloft expands downward into the colder or denser layer (Pollard et al. 1973; Petkovšek 1992). In order for such erosion to continue, the mechanical production of turbulence must also increase so as to offset the increased buoyant consumption. The semianalytic model applied by Petkovšek (1992) demonstrates that winds aloft must continually accelerate to produce progressive top-down turbulent erosion of CAPs. Numerical simulations by Vrhovec and Hrabar (1996) and Rakovec et al. (2002) help to confirm the accelerating wind criterion for CAP erosion, although their simulations lack sufficient resolution to explicitly resolve turbulent mixing.

Zhong et al. (2003) also rely on a semianalytic model to study CAP turbulent erosion due to shear instability across the CAP top. Turbulent erosion commences in their model when the bulk Richardson number for the uppermost layer of the CAP becomes subcritical, which can be expressed in terms of a threshold wind speed

$$
u \geq N d
$$

where $N$ and $d$ are representative scales for the static stability and the depth of the capping inversion layer, respectively. Their results indicate that for a given stratification and constant wind, the erosion rate decays with time such that turbulent erosion is unlikely by itself to dissipate a CAP.

The turbulent breakdown of stratification has also been studied for nocturnal stable boundary layers beneath low-level jets (Newsom and Banta 2003; Banta et al. 2003; Sun et al. 2012; Zhou and Chow 2014). Banta et al. (2003) formulate a jet bulk Richardson number:

$$
\mathrm{Ri}_{b}=\frac{g}{\theta} \frac{\Delta \theta / \Delta z}{\left(U_{x} / Z_{x}\right)^{2}},
$$


IOP 1
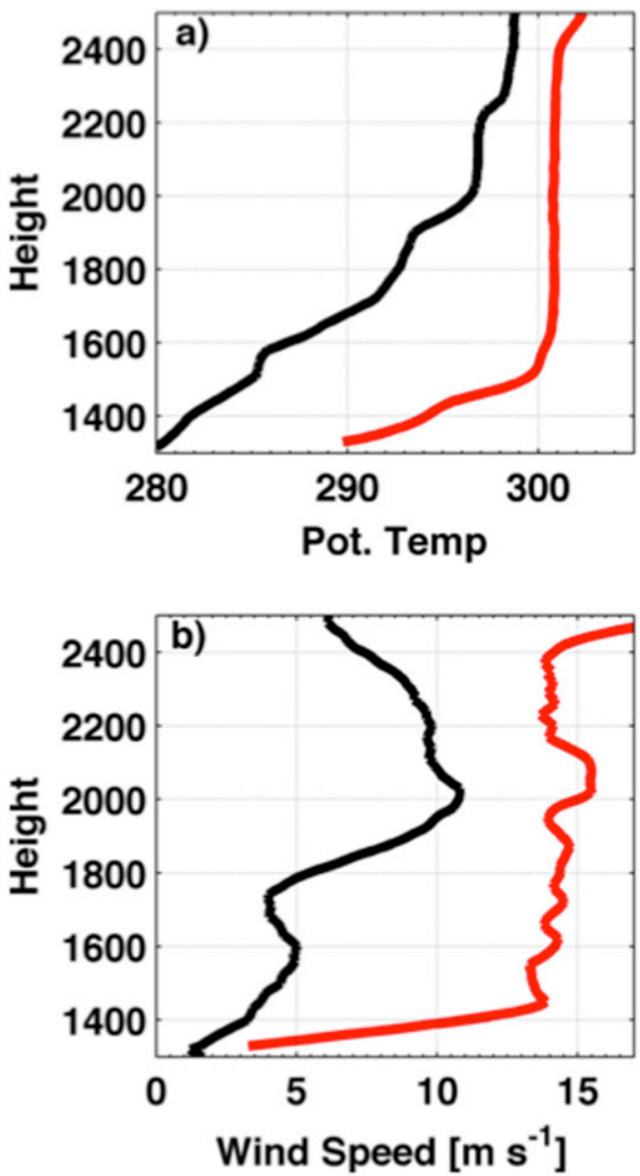

IOP 9
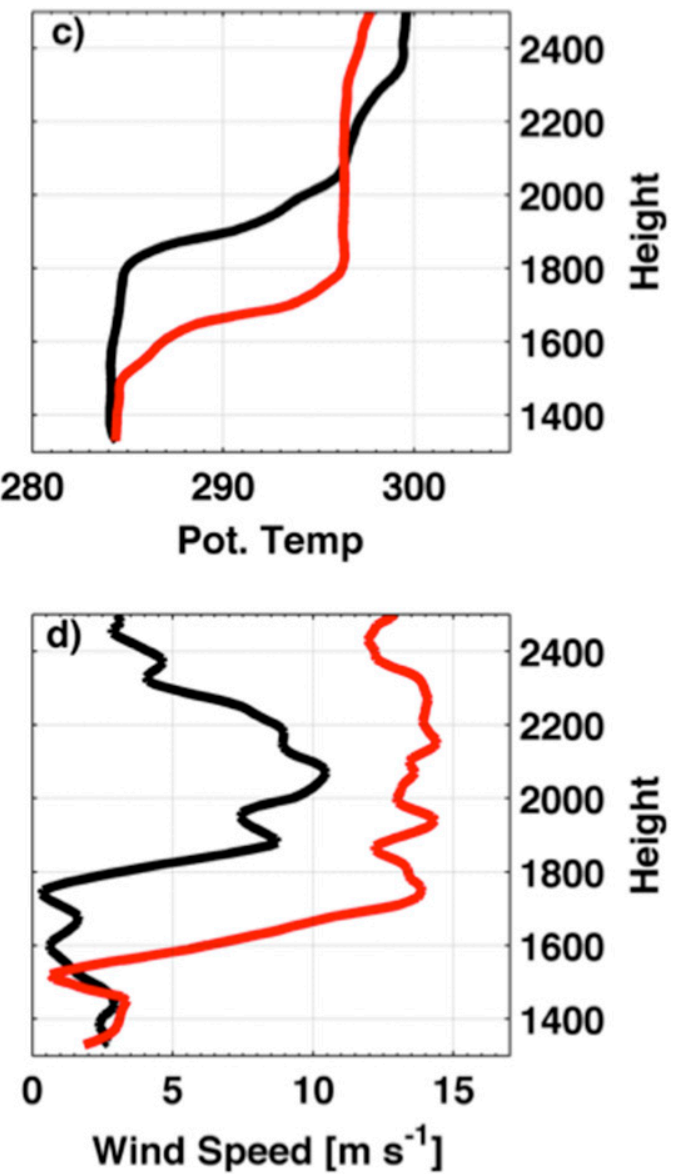

FIG. 1. Profiles of (a),(c) potential temperature and (b),(d) wind speed from PCAPS (left) IOP-1 and (right) IOP-9. The IOP-1 profiles are from 1200 UTC 2 Dec and 0600 UTC 3 Dec 2010. The IOP-9 profiles are from 1700 UTC $29 \mathrm{Jan}$ and 1200 UTC $30 \mathrm{Jan} 2011$. For each case, the black line is about $18 \mathrm{~h}$ prior to the red line.

where $U_{x}$ and $Z_{x}$ are the speed and height, respectively, of the low-level jet and the numerator represents the temperature deficit over the depth of the stable layer. Their observations indicate that the magnitude of turbulence within the stable layer is controlled by this bulk parameter rather than local gradients (Banta et al. 2003, 2006; Sun et al. 2012). When $\mathrm{Ri}_{b}$ is less than 0.3, turbulent fluxes of heat and momentum are significantly increased. It is worth noting that the bulk Richardson number is closely related to the aforementioned Froude number. Provided that linear profiles of shear and stability are assumed, as by Banta et al. (2003), the two dimensionless numbers are related by

$$
\mathrm{Ri}_{b}=1 / F^{2},
$$

where $H$ and $Z_{x}$ are assumed to be equivalent. This relationship points to a broader linkage between studies of turbulent mixing and valley flushing.
Despite previous research, aspects of CAP removal by strong winds aloft remain incompletely understood (Zardi and Whiteman 2013). For example, observations of wind-CAP interaction during the Persistent Cold-Air Pool Study (PCAPS; Lareau et al. 2013) in Utah's Salt Lake Valley reveal that CAP removal is sensitive to the strength and structure of stratification. Figure 1 demonstrates an aspect of this sensitivity by contrasting conditions during two intensive observing periods (IOPs), each affected by accelerating flow aloft. The IOP-1 CAP (Figs. 1a,b) thins substantially from about 700 to about $200 \mathrm{~m}$ over $18 \mathrm{~h}$ and is subsequently flushed from portions of the valley a short time later (Lareau and Horel 2015). The IOP-9 CAP (Figs. 1c,d) also thins from the top down, but the reduction is less that in IOP-1 and surface conditions remain decoupled despite comparable flow aloft. A key difference between the profiles is the structure of the CAP: IOP-1 is linearly stratified, whereas IOP-9 exhibits a sharp capping 

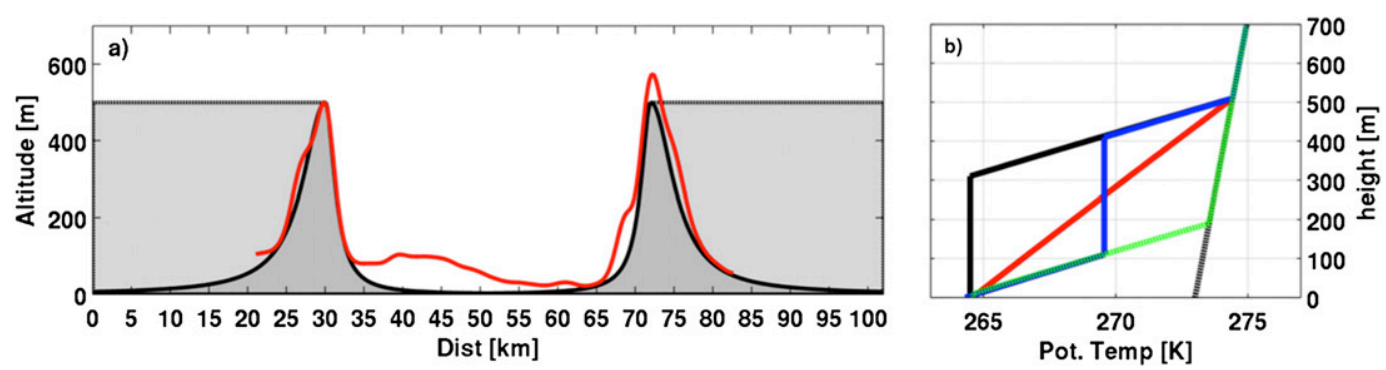

FIG. 2. Summary of numerical experiment design. (a) Model topography: mountain (e.g., control) topography (solid black line and dark gray shading) and plain topography (black line and light gray shading). The red line is a smoothed south-north transect of the Salt Lake Valley, UT. (b) CAP potential temperature profiles: linear (e.g., control, red), multilayer (blue), capping layer (black), shallow (dashed green), and inflow profile (gray).

inversion layer above a partially mixed surface-based layer.

While these PCAPS observations highlight the importance of top-down removal of CAPs, the experimental design was not directed toward measurements of turbulent heat and momentum fluxes at the CAP top. As such, it is difficult to diagnose the underlying differences in the rate of CAP removal as a function of stratification. Hence, in this study we use idealized high-resolution simulations to examine the turbulent and advective processes contributing to CAP breakup. The extent to which the broad parameter space of wind speeds aloft, stability profiles, and topographic details can be summarized succinctly is explored through a series of sensitivity experiments. The setup and details of these simulations are described in section 2. Results are then presented in section 3, including how a "CAP Froude number" can be used to better understand CAP removal. A quick comparison and discussion of the model simulations relative to conditions during PCAPS IOP-1 follows in section 4 . Finally, section 5 summarizes our findings.

\section{Experimental setup}

\section{a. Numerical model}

The simulations in this study are executed using version 3.4 of the Weather Research and Forecasting (WRF) Model (Skamarock et al. 2008). The model is configured as an idealized large-eddy simulation (LES) so as to explicitly resolve the turbulent mixing of heat and momentum between CAPs and their ambient environment. In contrast, most previous numerical investigations of CAP breakup (e.g., Rakovec et al. 2002) rely on parameterization of these turbulent motions. For guidance in selecting sufficient grid spacing, we follow Skamarock (2014), who shows that for WRF to reproduce benchmark simulations of a gravity current (Straka et al. 1993) the horizontal grid spacing should be less than or equal to $100 \mathrm{~m}$ and that high-order finite differencing is required. Since the buoyancy and velocity scales of our CAP cases are similar to those of the gravity current, we choose $\Delta x=\Delta y=50 \mathrm{~m}$ and use fifth-order upwind horizontal advection. The vertical grid is stretched over 100 levels from the surface to $10 \mathrm{~km}$ such that the resolution within the first $500 \mathrm{~m}$ ranges from 14 to $30 \mathrm{~m}$. The near-surface grid spacing is sufficient because we use a mature CAP as our initialization and are not concerned with slope flows or radiative cooling. The model time step is $0.5 \mathrm{~s}$ to accommodate the high-resolution grid.

The domain is a rectangular slab that is $102 \mathrm{~km}$ long (streamwise) by $1 \mathrm{~km}$ wide. The streamwise boundaries use a 5-km lateral Rayleigh damping layer that adjusts the model toward prescribed inflow at each time step. The upper boundary also uses a Rayleigh damping to prevent spurious wave reflection. The spanwise boundaries are periodic.

Since we are interested only in the dynamics of windinduced CAP removal, we turn off surface heat flux, radiation, and microphysics parameterizations. Surface momentum fluxes are, however, parameterized using a Monin-Obukhov surface layer. On the scale of our experiments, the Rossby number is sufficiently large so as to neglect rotation.

\section{b. Control experiment}

The basic dynamics of wind-induced CAP removal are examined using a linearly stratified $\left(N=0.027 \mathrm{~s}^{-1}\right) \mathrm{CAP}$ confined between two 500-m mountain ridges (Fig. 2) while the environment external to the CAP is more weakly stratified $\left(N=0.01 \mathrm{~s}^{-1}\right)$. The cold air fills the valley such that the temperature difference across the CAP is $10 \mathrm{~K}$, which is comparable to CAPs observed during PCAPS (see Fig. 1). The topography is also loosely based on a south-north transect of the Salt Lake Valley: ridge crests are separated by $42 \mathrm{~km}$ and the valley floor is about $20 \mathrm{~km}$ across. The maximum valley slope angle is about $12^{\circ}$ while 
TABLE 1. Properties of each CAP profile used in this study. BH is the column-integrated buoyancy, defined in the text, and $N_{\max }$ is the maximum Brunt-Väisälä Frequency.

\begin{tabular}{lccc}
\hline \hline CAP profile & $\begin{array}{c}\text { Surface temperature } \\
\text { deficit }(\mathrm{K})\end{array}$ & $\mathrm{BH}\left(\mathrm{m}^{2} \mathrm{~s}^{-2}\right)$ & $N_{\text {max }}\left(\mathrm{s}^{-1}\right)$ \\
\hline Linear & 10 & 82.8 & 0.027 \\
Multilayer & 10 & 82.8 & 0.043 \\
Capping layer & 10 & 138.4 & 0.043 \\
Shallow layer & 10 & 36.7 & 0.043 \\
\hline
\end{tabular}

the outer mountain slopes are more gradual with a maximum of about $5^{\circ}$. Random noise with a mean of $2.5 \mathrm{~m}$ and a maximum of $5 \mathrm{~m}$ is added to the topography to generate minor variations in the inflow, which in turn produces more realistic waves and turbulence within the CAP as compared to smooth topography.

To test CAP response to accelerating wind, the inflow is linearly increased from 0.5 to $25 \mathrm{~m} \mathrm{~s}^{-1}$ over the 20 -h simulation $\left(3.4 \times 10^{-4} \mathrm{~m} \mathrm{~s}^{-2}\right)$. Similar accelerations were documented during PCAPS IOP-1 and are relatively common in the Salt Lake Valley. We impose a 100-m-deep logarithmic boundary layer shear profile at the inflow boundary. The flow adjusts away from the imposed profile as it moves through the upstream portion of the domain, developing a mechanically mixed boundary layer before interacting with the CAP.

\section{c. Sensitivity experiments}

The sensitivity of CAP removal to the strength of stratification and the total amount of cold air that must be scoured from the valley is tested using four initial CAP profiles: linear (control), capping layer, multilayered, and shallow layer (Fig. 2b). Each profile is constructed with the same surface temperature deficit $(10 \mathrm{~K})$ but varies either in maximum stability or column-integrated negative buoyancy:

$$
\mathrm{BH}=-g \int_{0}^{H}\left[\frac{\theta(z)-\theta(H)}{\theta(H)}\right] d z,
$$

where $H=500 \mathrm{~m}$ is the depth of the valley and $\theta(H)$ is the potential temperature at the valley top (initially $274 \mathrm{~K}$ ), such that the CAP's initial negative buoyancy is relative to a dry adiabatic profile. The negative sign is used for convenience. Note that $\mathrm{BH}$ is sensitive to both the depth and the strength of the stratification and is similar to the column heat deficit presented by Whiteman et al. (1999). A summary of the properties for each CAP profile is provided in Table 1.

The destruction of each CAP by accelerating wind is subsequently simulated using two different terrain configurations: 1) "mountain" and 2) "plain" (Fig. 2). The mountain terrain is the control topography, whereas the plain configuration replaces the outer mountain slopes with constant height surfaces extending to the model boundaries. The valley shape is unaltered between cases, thereby testing how upstream flow-topography interaction affects the time scale and spatial structure of CAP removal. For example, the two terrains differ in terms of their basic mountain wave response to the linearly stratified inflowing airstream. The mountain cases tend to produce more flow into the valley along the upwind valley slopes, whereas the plain cases exhibit greater flow separation.

\section{d. CAP Froude number}

An advantage of defining the CAP strength in terms of the layer-integrated buoyancy is that it is possible to reduce a portion of the parameter space of our experiments by defining a CAP Froude number:

$$
\mathrm{Fr}=\frac{U}{\sqrt{\mathrm{BH}}},
$$

where $U$ is the maximum wind speed above the CAP and the denominator replaces a common approximation for NH (Grainger and Meroney 1993; Reinecke and Durran 2008):

$$
N H \cong \sqrt{\frac{g}{\bar{\theta}} \frac{\theta_{\text {top }}-\theta_{\text {bot }}}{H}} \times H .
$$

The CAP Froude number better differentiates between cases with variations in stratification within CAPs as examined in this study; that is, there are no differences in $\mathrm{NH}$ using the conventional approximation between any of the four CAP profiles shown in Fig. 2. Moreover, as the CAP profile approaches that of a two-layer stratified system (e.g., knife-edge capping inversion), $\sqrt{\mathrm{BH}}$ approaches the conventional shallow-water gravity speed $\sqrt{g^{\prime} h}$. Rather than the common, and difficult, requirement for other terrain-flow interactions to specify the upstream wind speed impinging on the upstream terrain, Fr is defined here in terms of the maximum wind above the CAP. Hence, it is possible from a profile within the valley to define Fr relevant for CAP removal.

\section{Results}

\section{a. Control case: Linear CAP, mountain topography}

This section highlights the key dynamics of windinduced CAP breakup by examining the control simulation. Figure 3 shows 20 -min-mean cross sections of the CAP at successive inflow wind speeds of 5, 10, and $15 \mathrm{~m} \mathrm{~s}^{-1}$ corresponding to 221,466 , and $711 \mathrm{~min}$ into the simulation, respectively. The 20-min means are centered on these times. 

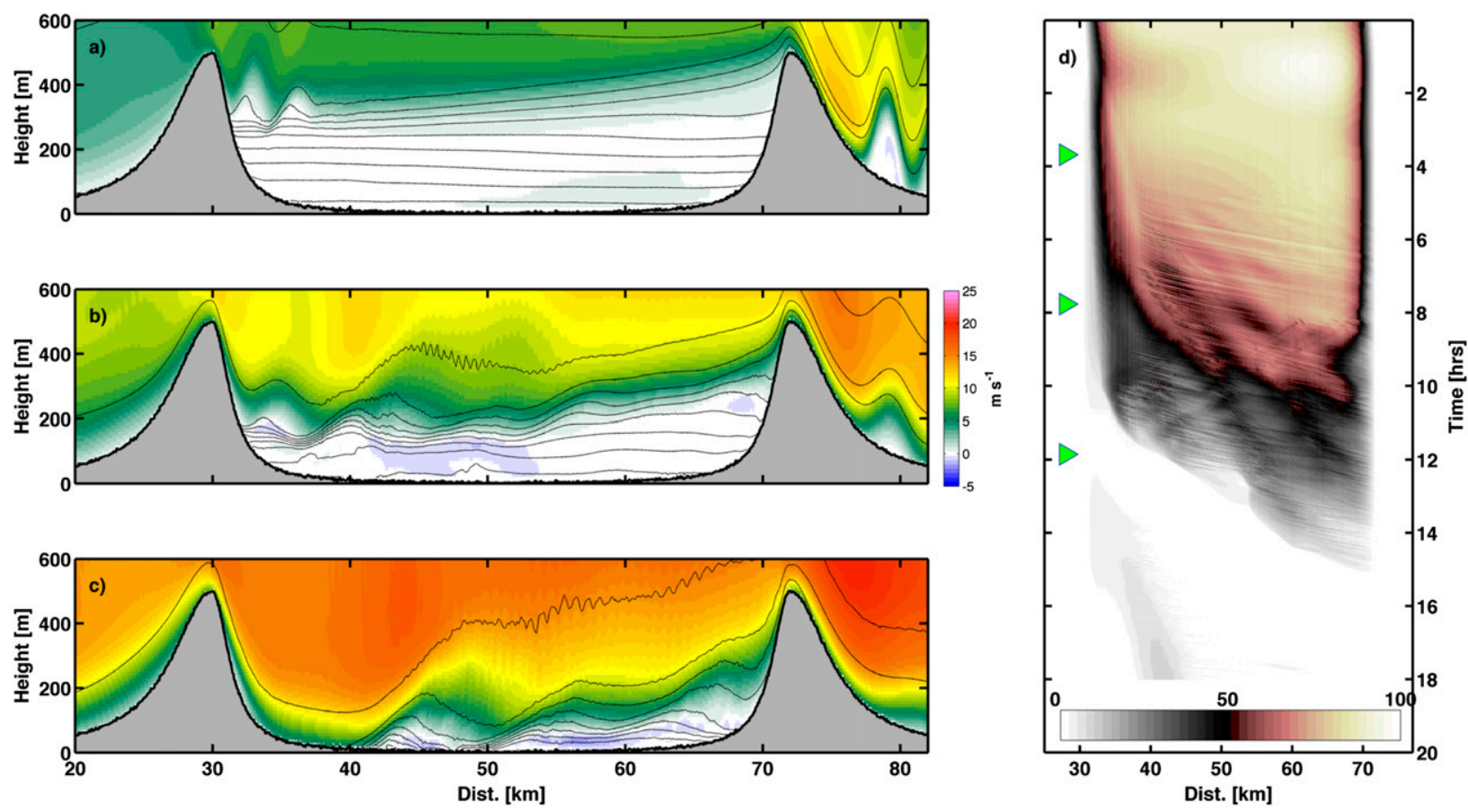

FIG. 3. The 20-min time-mean cross sections taken along the center of the spanwise domain of potential temperature (contour interval is $1 \mathrm{~K}$ ) and wind speed (shading) for the linear CAP mountain case at (a) 5, (b) 10, and (c) $15 \mathrm{~m} \mathrm{~s}^{-1}$ inflow. (d) Time-distance distribution of column-integrated buoyancy.

Figure 3a shows that the initial horizontally homogenous CAP responds to the acceleration of the inflow to $5 \mathrm{~m} \mathrm{~s}^{-1}$ by tilting in the downwind direction such that the CAP depth is decreased (increased) at the windward (downwind) end of the valley. The difference in CAP depth across the valley is approximately $200 \mathrm{~m}$. At the downwind edge of the valley, blocked flow below is separated from a thin slice of the upper layer of the CAP (e.g., the top three isentropes) that possesses sufficient momentum to surmount the downstream ridge, thus removing cold air from the valley via "spillover" (Zängl 2003). Vertical wind shear is concentrated in a shallow layer near the CAP top, since the upper layer of the CAP is flowing downstream while the remainder of the CAP is nearly stagnant. At the windward end of the basin, two low-amplitude waves generated by the upstream mountain ridge locally affect the stability the top of the CAP.

As the flow continues to accelerate to a speed of $10 \mathrm{~m} \mathrm{~s}^{-1}$ over the next several hours (Fig. 3b), the CAP has thinned to a mean depth of about $300 \mathrm{~m}$ and continues to exhibit a downstream incline and spillover. Compared to its initial state, the stability at the CAP top has increased (e.g., tighter vertical gradient in potential temperature). The CAP also exhibits a series of wavelike undulations wherein the local CAP depth and stratification vary along the valley. The first two undulations are associated with lee waves from the upstream mountain, while the remaining wavelike variations are less clearly linked with the upstream terrain. The flow within the CAP remains weak with some regions of reversed flow (blue shading), implying a dynamical response arising from the blocked flow farther downstream.

After $12 \mathrm{~h}$ and acceleration of the inflow to $15 \mathrm{~m} \mathrm{~s}^{-1}$ (Fig. 3c), the CAP is removed from the windward third of the valley and thinned to a mean depth of about $150 \mathrm{~m}$ along the remaining downwind fetch. The downwind incline persists, though spillover is less due to the increased separation between the CAP top and the ridge crest. A front separates the stagnant cold air from the warmer, windier air sweeping into the basin. This front advances through the valley leading to a steplike jump in surface temperature of about $10 \mathrm{~K}$ as it passes (not shown). The previously identified undulations in the CAP depth persist with the windward side of each undulation exhibiting both stronger stratification and stronger shear as compared to its downwind side.

To further summarize the CAP removal, $\mathrm{BH}$ is shown in Fig. $3 \mathrm{~d}$ as a function of time and along-valley distance. Commensurate with the CAP thinning throughout the simulation, $\mathrm{BH}$ progressively diminishes with time and increasing wind speed. The CAP tilting is apparent as greater $\mathrm{BH}$ for the downwind portion of the basin at a given time and subsequently reflected in the pattern of CAP removal (e.g., BH approaches zero), which occurs 

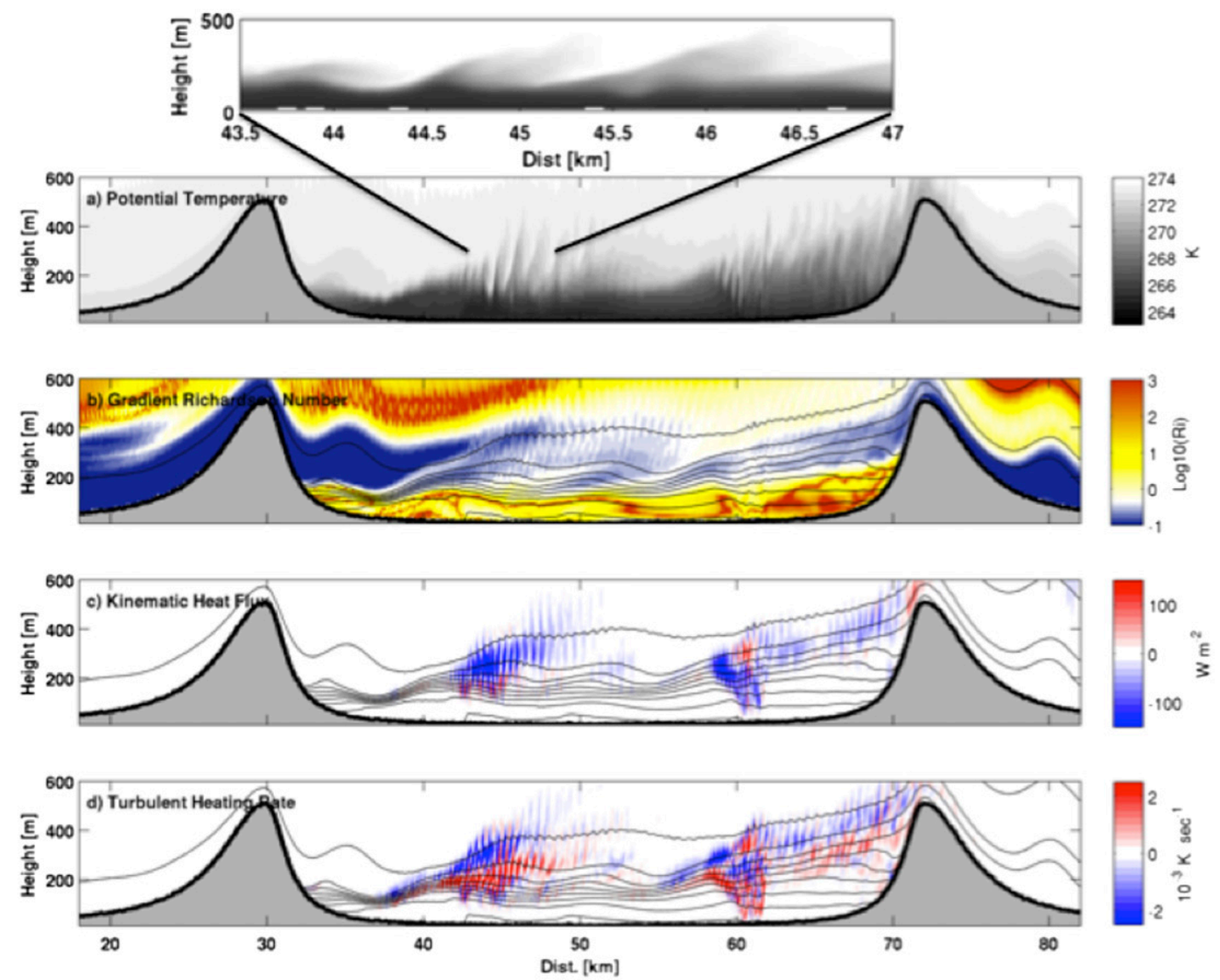

FIG. 4. Snapshot of waves impacting the CAP at $500 \mathrm{~min}\left(11 \mathrm{~m} \mathrm{~s}^{-1}\right)$ : (a) potential temperature, (b) $\log$ base 10 of the gradient Richardson number (blue shading for subcritical values), (c) kinematic heat flux, and (d) turbulent heating rate. Contours in (b)-(d) are potential temperature every $1 \mathrm{~K}$. (top) Detail of the Kelvin-Helmholtz waves in equal aspect ratio. The cross section is taken along the center of the spanwise domain.

first at the upwind end of the valley at around $12 \mathrm{~h}$, then progresses downwind before final CAP eradication around $15 \mathrm{~h}$ when the inflow is about $19 \mathrm{~m} \mathrm{~s}^{-1}$. The front separating CAP air from warmer flow propagates at a rate of about $2.8 \mathrm{~m} \mathrm{~s}^{-1}$, though its motion is somewhat discontinuous owing to meso- $\gamma(5-10 \mathrm{~km})$ variations in the CAP depth.

In addition to the CAP thinning and tilting, waves at multiple scales and phase speeds are affecting the CAP (Fig. 3d). For example, the lee waves apparent in Figs. 3a-c have a pronounced signature that slowly moves downstream owing to the increasing inflow velocity. Many smaller-scale waves are also apparent as striations tending to originate proximal to the lee wave and progressing downstream at a rate roughly that of the ambient flow. The meso- $\gamma$ CAP undulations are also evident as variations in $\mathrm{BH}$ that propagate downstream at a rate greater than that of the lee wave but much slower than the smaller-scale waves.

A snapshot of these smaller-scale waves and their contribution to CAP destruction is presented in Fig. 4 (see the online supplemental material for an animation). At $500 \mathrm{~min}$, the top of the CAP is populated with numerous perturbations, many exhibiting the characteristic billow of Kelvin-Helmholtz waves (KHWs). These KHWs have amplitudes of 100-200 m and wavelengths of $0.5-1 \mathrm{~km}$ (inset, Fig. 4). KHWs form in stratified shear flow when the magnitude of the shear exceeds the damping effects of the stratification (Nappo 2002) - a condition given by the critical gradient Richardson number

$$
\mathrm{Ri}_{g}=\frac{N^{2}}{(\partial u / \partial z)^{2}+(\partial v / \partial z)^{2}} \leq 0.25
$$

where the terms in the denominator are the components of the vertical shear. It is apparent from Fig. $4 \mathrm{~b}$ that the simulated KHWs form in regions of subcritical $\mathrm{Ri}_{g}$ (blue shading) within the uppermost layers of the CAP. For example, small wavelike perturbations first appear starting near $37 \mathrm{~km}$ in a narrow filament at the CAP top where subcritical $\mathrm{Ri}_{g}$ coincides with strong static stability, reflecting dynamically unstable stratified shear flow. This 

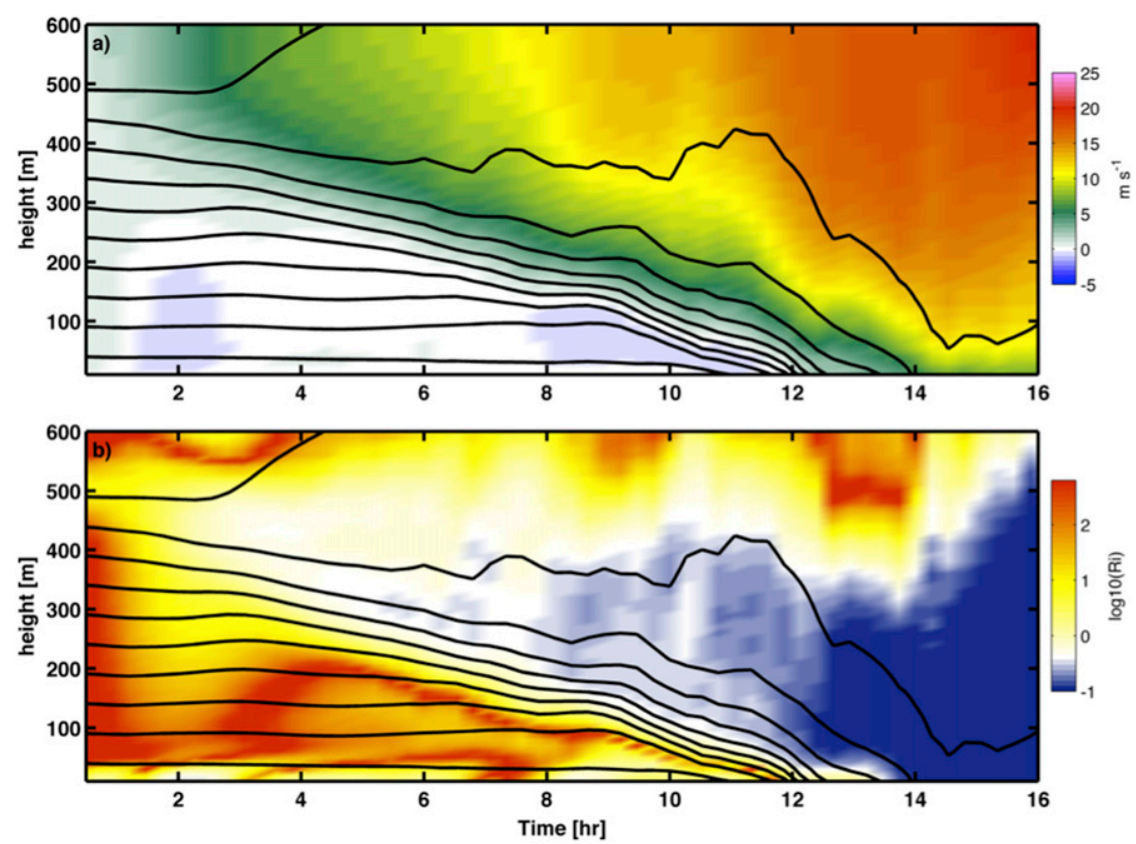

FIG. 5. Time-height evolution of (a) wind speed and (b) log base 10 of the gradient Richardson number for the valley-mean column. Contours are potential temperature every $1 \mathrm{~K}$.

dynamically unstable layer is distinct from the more extensive layer of subcritical $\mathrm{Ri}_{g}$ associated with the turbulent boundary layer that is advected into the basin. These nascent KHWs subsequently grow downstream, becoming breaking waves before diminishing into a region of reduced stratification and shear near $47 \mathrm{~km}$. The meso- $\gamma$ undulations previously described in the $20-\mathrm{min}$ averages (Figs. 3b,c) simply reflect the impact of averaging the shear and stratification associated with the KHWs.

The kinematic turbulent heat flux due to these KHWs is assessed using 15-min Reynolds averages (Fig. 4c). Since the KHWs transport cold air upward and warm air downward, localized regions of strong negative heat flux $\left(-100-150 \mathrm{~W} \mathrm{~m}^{2}\right)$ are evident in Fig. 4c. The resulting turbulent heating rate (i.e., the flux divergence) manifests as a vertical couplet of cooling above and warming within the CAP (Fig. 4d). This process contributes to the generation of an intermediary layer of air above the primary CAP that is cooler than the air aloft and warmer than the air inside the CAP.

The relationships between shear, stratification, and KHWs are illustrated in Fig. 5 by examining the valleymean atmospheric column as a function of time and height. The mean column is evaluated as the streamwise mean from 35 to $65 \mathrm{~km}$ along the spanwise centerline of the domain, representative of the conditions along and above the valley floor. The top of the CAP progressively lowers and also becomes increasingly stable. The peak stability just before the CAP is destroyed is $N \sim 0.055 \mathrm{~s}^{-1}$ and more than twice that at the initial time. The strong winds extending downward into the basin maintain strong shear at the CAP top (Fig. 5a). The strength of the shear and that of the stratification vary roughly in concert, thereby maintaining a region of near-critical gradient Richardson number along the CAP top that continually supports KHWs (Fig. 5b). The KHWs accomplish this mutual adjustment by redistributing heat and momentum.

KHWs alone, however, cannot remove the CAP. Advection also contributes to the transport of cold air out of the valley. This interplay between advection and KHWs is examined in terms of the heat budget computed locally at every location and then averaged to obtain a valleymean column:

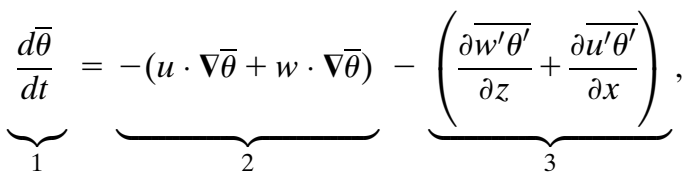

where term 1 is the local time rate of change of the 15-min Reynold's mean potential temperature that is forced by the terms on the right-hand side: the heating or cooling due to mean advection (term 2) and turbulent heat flux divergence (term 3). There is no radiative heating term since radiation is ignored. Each term of the heat budget is shown in Fig. 6 along with the contours of mean potential temperature. 


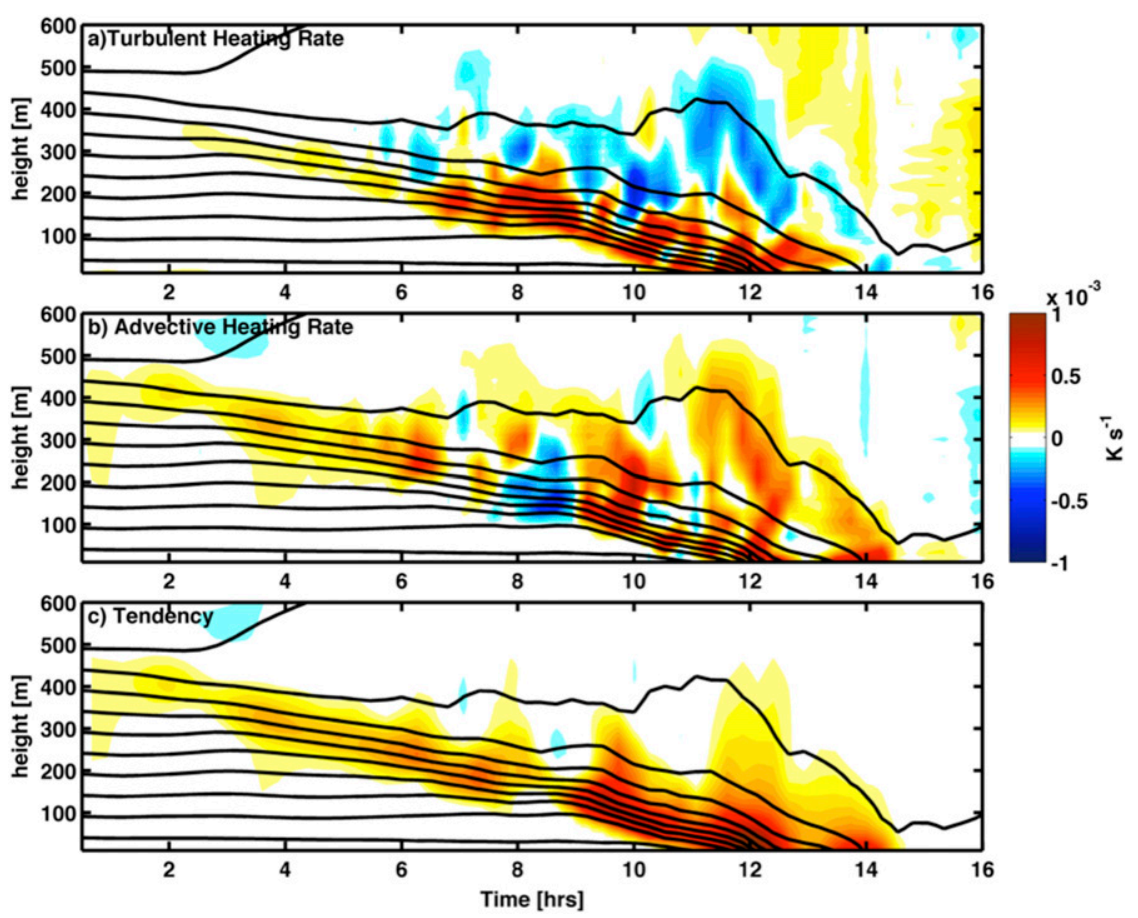

FIG. 6. Time-height evolution of the heat budget for the valley-mean column. (a) Turbulent heating rate, (b) advective heating rate, and (c) net heating tendency. Contours are potential temperature every $1 \mathrm{~K}$.

Averaged over the entire valley, substantive turbulent heating commences after about $5 \mathrm{~h}$ (Fig. 6a), corresponding to the onset of KHWs during the transition to subcritical gradient Richardson number at the top edge of the CAP (Fig. 5b). The heating rate is then, in general, positive within the top edge of the CAP and negative above, as previously shown in the snapshot in Fig. 4. The regions of positive heating closely align with the increased static stability in the capping layer. This pattern is consistent with theories for top-down turbulent erosion, which predict that the lowering of the mixed layer generates a localized increase in the buoyancy contrast between layers (Pollard et al. 1973; Price et al. 1978; Petkovšek 1992). The turbulent heating rate is predominately negative above the CAP, indicating that the breaking waves redistribute the colder, denser air into the mixed layer aloft, which tends to raise the potential energy of the system.

In contrast to the vertical dipole in the turbulent heating rate, the net advective heating rate (term 2) is generally positive at and above the CAP top, with only ephemeral periods of cooling, which are associated with gravity currents and internal waves within the CAP (Fig. 6b). Importantly, advection warms the mixed layer aloft-the same region that KHWs continuously cool with an almost one-to-one relationship between periods of advective warming and turbulent cooling. Hence, the mixed-layer temperature remains roughly constant throughout the simulation.

Advective heating of the valley atmosphere is also important prior to the onset of KHWs since the only way to lower the CAP during the first $5 \mathrm{~h}$ of the simulation is the laminar spillover of the cold air out of the valley. Thus, there appear to be two regimes in the CAP removal: the first is dominated by spillover while the second corresponds to a combination of KHWs and advection. In the net, the two processes act together to destroy the CAP from the top down, which is shown in Fig. $6 \mathrm{c}$ in terms of the mean potential temperature tendency (term 1).

The top-down destruction of the CAP for the control case can be summarized as follows:

- Winds increase aloft, transferring momentum into the upper layers of the stratified air mass. The uppermost layers of the CAP are then advected downstream and over the topography, reducing the CAP by spillover.

- As the winds aloft continue to increase, a critical threshold is reached within the sheared upper layers of the CAP that leads to the breakdown of stratification into KHWs. These KHWs mix cold air upward and warm air downward, resulting in an "intermediary layer" of air that is potentially warmer than the CAP but cooler than the flow aloft.

- The intermediary layer is subsequently scoured from the CAP top and advected downwind and eventually 

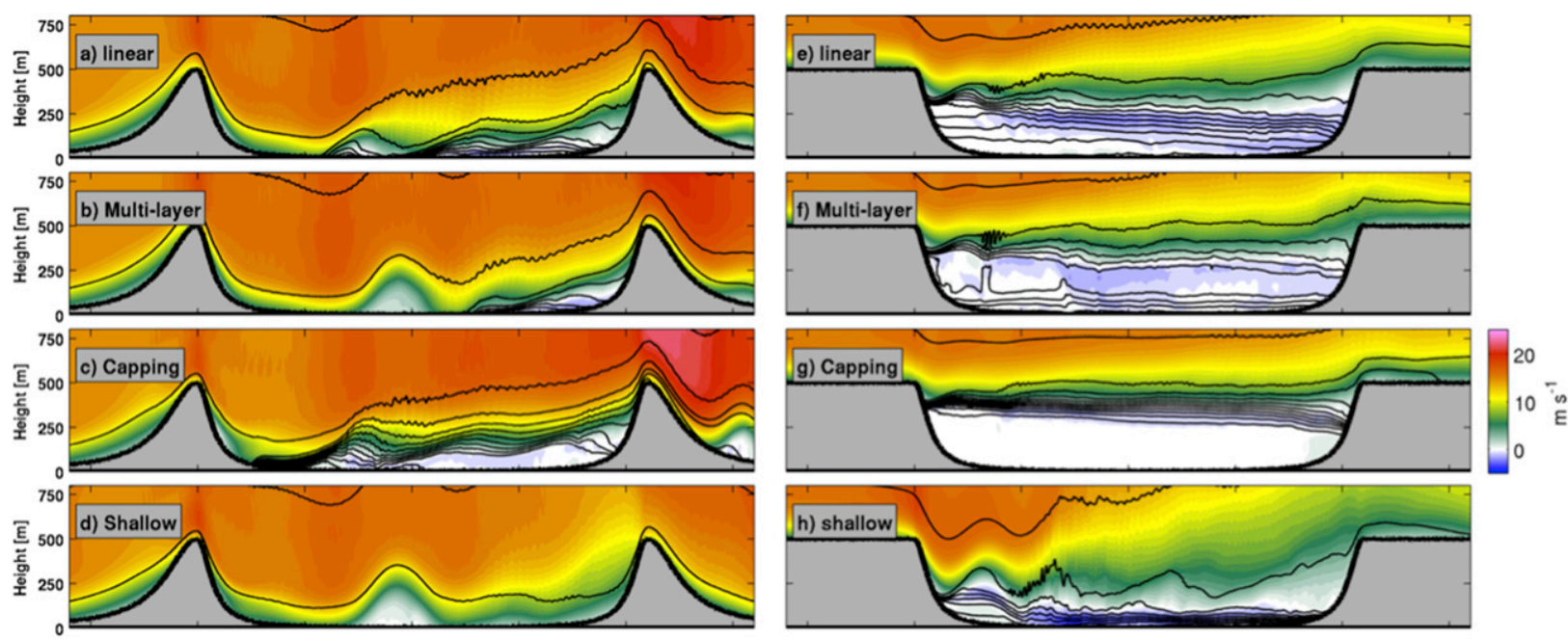

FIG. 7. Snapshots of each experimental run at $15 \mathrm{~m} \mathrm{~s}^{-1}$ inflow. (a)-(d) Mountain and (e)-(h) plain simulations. The profiles are labeled in the figure.

out of the basin. The warmer inflowing air replaces the intermediary layer, thus progressively lowering and sharpening the CAP.

\section{b. Sensitivity results}

\section{1) Overview}

In this section, we investigate how the time scale and structure of CAP removal varies with stratification and terrain. Many of the basic features of these sensitivities are revealed in 20-min-mean cross sections of each simulation when the inflow speed reaches $15 \mathrm{~m} \mathrm{~s}^{-1}$ (after about $12 \mathrm{~h}$; Fig. 7). It is immediately apparent that the CAPs in mountain cases are removed more effectively than those in the plain cases. Each mountain CAP is inclined in the downstream direction and displaced (or eradicated entirely) by the warmer inflowing air at the windward end of the valley. For the plain cases, the valley atmosphere remains largely decoupled from the flow aloft with only minor reductions in CAP strength. The plain cases also exhibit organized reversed flow and a modest upstream incline such that the greatest CAP depth is found near the windward end of the valley. As a result, the spillover in the plain cases is comparatively less than in the mountain runs.

Comparing the simulations with differing stability profiles, the shallow CAPs are most affected by the accelerating flow and, in the case of the mountain terrain, completely removed. The capping-layer cases are least affected, with, for example, the plain case nearly unaltered after $12 \mathrm{~h}$. In that case, the CAP serves as an impermeable barrier and the flow aloft proceeds across the valley as if the valley were not present. The multilayered and linear CAPs, which start from the same value of $\mathrm{BH}$, are more similarly eroded.
These basic inferences regarding the sensitivity of CAP removal to the terrain and stability profiles are confirmed by examining the time-distance evolution of $\mathrm{BH}$ for each case (Fig. 8). As expected, the terrain sensitivity is large: the mountain CAPs are removed after $11-15 \mathrm{~h}$ compared to 14 to more than $20 \mathrm{~h}$ for the plain cases. In addition, whereas the plain cases maintain a steady-state CAP until much later into those simulations, the reduction of $\mathrm{BH}$ in the mountain cases commences shortly after initialization. The terrain also affects the spatial pattern of CAP removal. As seen in Fig. 7, the mountain cases experience a pronounced downwind incline, which leads to the CAP removal advancing downwind through the valley (Figs. 8a-d). In contrast, the plain cases maintain a vestigial pocket of cold air near the windward end of the valley and do not exhibit a clear downwind frontal propagation during removal (Figs. 8e-h). This key morphologic difference is associated with separation eddies that form in the plain cases as the flow detaches from the inflow plain at the valley crest, thus sheltering the windward end of the valley. The mountain simulations, on the other hand, experience plunging flow in the same region because of higher-amplitude mountain waves, which help to displace the CAP.

Terrain-flow interactions are also a key component of the difference in CAP removal time scale (Fig. 9). For the mountain cases, the flow above the CAP tracks closely with the prescribed inflow velocity, whereas for the plain cases, it is systematically reduced. This difference is related to the conservation of mass through the model domain. For the plain cases, the total depth of the flow increases to fill the valley as the CAP is removed (analogous to a widening-pipe flow), requiring the column-mean velocity to diminish. Thus, the differences 

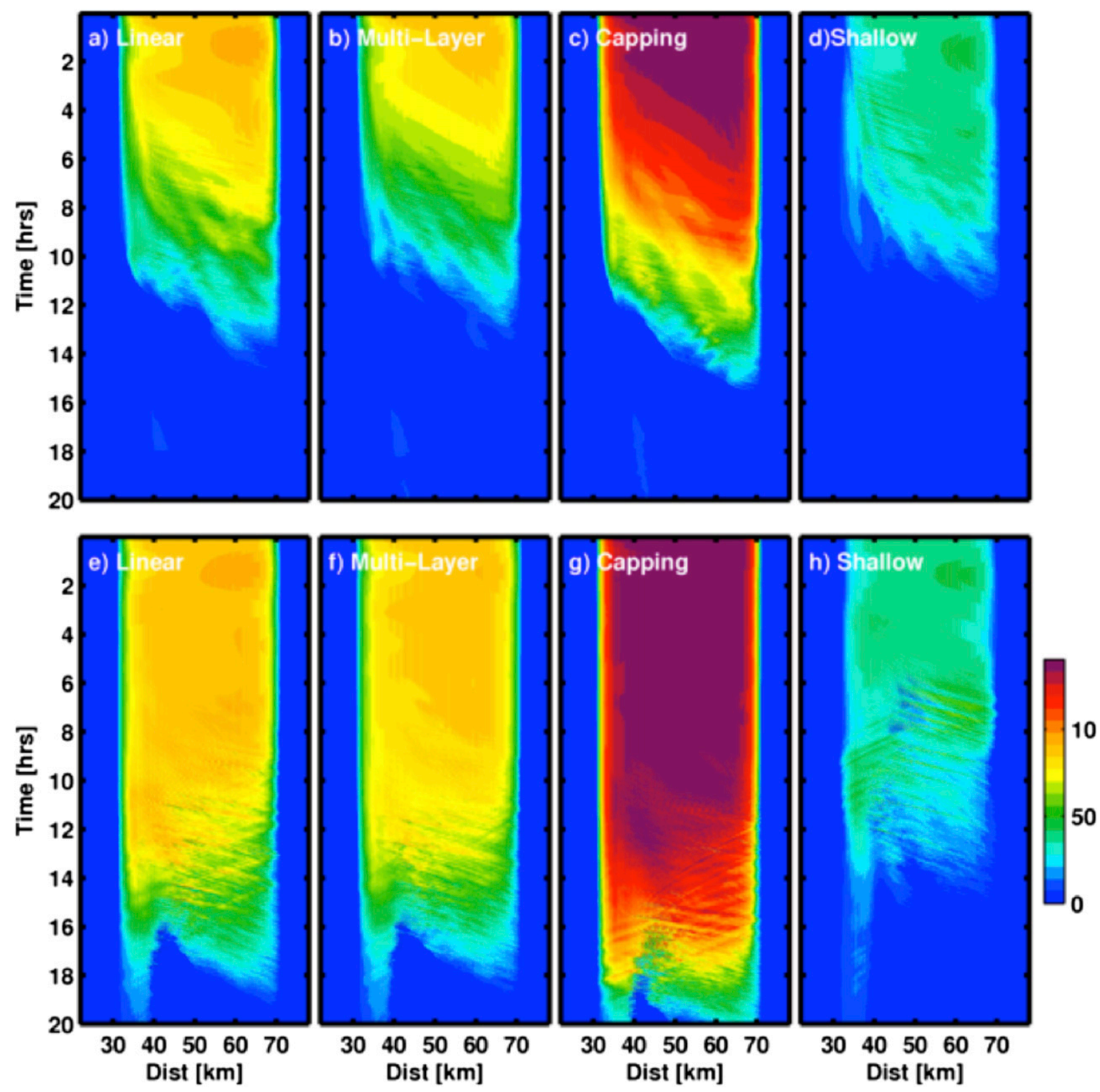

FIG. 8. Time-distance evolution of the column-integrated buoyancy for each case. (a)-(d) Mountain and (e)-(h) plain simulations. The profiles are labeled in the figure.

between the valley and plain cases arise not simply because of terrain geometry but also because of the impact of the terrain on the strength of the flow aloft impinging on the CAP.

As shown in Fig. 10, the sensitivity to initial stratification is also pronounced, accounting for multihour differences in the timing of CAP removal. First, the greater the initial value of $\mathrm{BH}$ is (averaged over the valley), the longer it takes to remove the CAP. For example, the shallow cases are removed much sooner than the capping layer cases regardless of the terrain. Moreover, the multilayer and linear CAP profiles, which have the same initial value of $\mathrm{BH}$ but differ in their peak stability within the CAP, are removed in comparable times. This result suggests that the total amount of cold air in the basin is more important than the maximum stability within the CAP. In addition, Fig. 10 clearly shows that the greater the initial value of $\mathrm{BH}$, the greater the eventual rate of cold-air removal from the basin, reflecting that the instantaneous heat flux magnitude is proportional the value of BH. For example, the capping, linear, multilayer, and shallow stability profiles lead to successively slower rates 


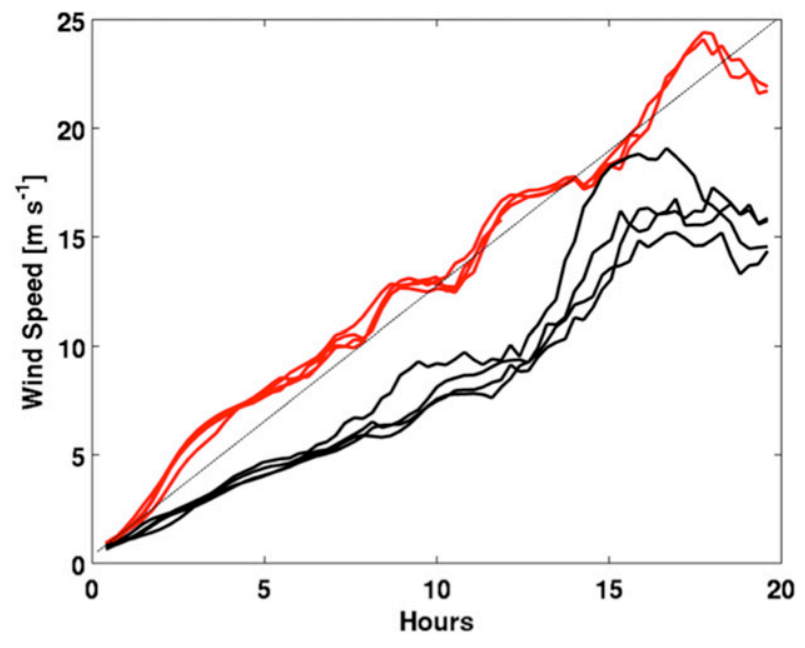

FIG. 9. Mean wind at $500 \mathrm{~m}$ above the valley floor for the mountain (red) and plain cases (black). The dashed line is prescribed inflow velocity.

of cold-air removal. This effect tends to converge the times required to remove weaker and stronger CAPs.

As in the control simulation, the CAP reduction in all cases proceeds as a continual top-down turbulent erosion, wherein the lowering of the CAP top produces a very sharp, shallow layer of cold air just before removal (not shown). There are, however, distinct differences in the time evolution of the maximum stability among the stability profiles (Fig. 11). Compared to the initial stratification, the maximum stratification in the linear profiles continuously increases, approaching a value nearly twice that at initialization (red markers, Fig. 11). In contrast, the multilayer CAPs experience a gradual decrease in stratification as the upper inversion layer is removed and the internal adiabatic layer is mixed into the flow aloft (blue markers, Fig. 11). The stratification then increases as the CAP top reaches the lower inversion layer. The capping and shallow profiles, which both start with comparable layers of strong stability, experience little change in strength for most of the run then spike to higher values as the CAP top approaches the ground. In terms of the actual values of peak stability, each case approaches a value of $N \sim 0.055 \mathrm{~s}^{-1}$ just prior to removal (not shown). This is roughly equivalent to a $10-\mathrm{K}$ inversion over $100 \mathrm{~m}$, which is consistent with the tendency for the temperature to remain unchanged until the final destruction of the CAP.

\section{2) CAP Froude NuMBer}

In light of the pronounced wind speed and buoyancy differences between simulations, it is useful to recast the basic sensitivity results in terms of $\mathrm{Fr}$ in order to succinctly delineate many of the key aspects of CAP

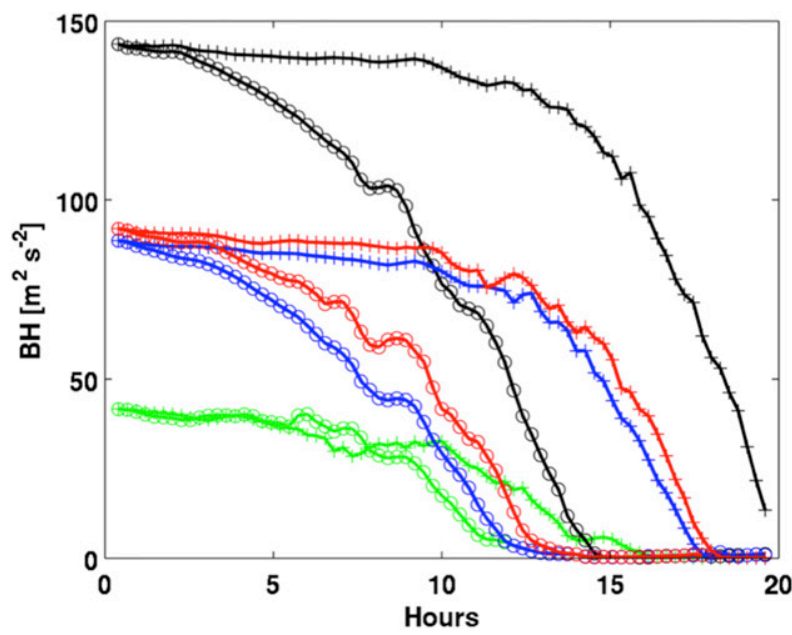

FIG. 10. Column-integrated buoyancy as a function of time for each case. Circles represent the mountain cases and plus signs represent the plain cases. Colors correspond to the different profiles: linear (red), multilayer (blue), capping layer (black), and shallow layer (green).

breakup. Figure 12 shows the time-distance evolution of each CAP in terms of Fr. Compared to Fig. 8, it is now clear that each case progresses through the same parameter space en route to breakup. Irrespective of initial stratification or terrain, Fr first smoothly increases from 0 to 1 as the wind aloft accelerates. Then, at $\mathrm{Fr} \sim 1$, the CAPs develop small waves, apparent as finescale variations in Fig. 12. Wave activity then amplifies with

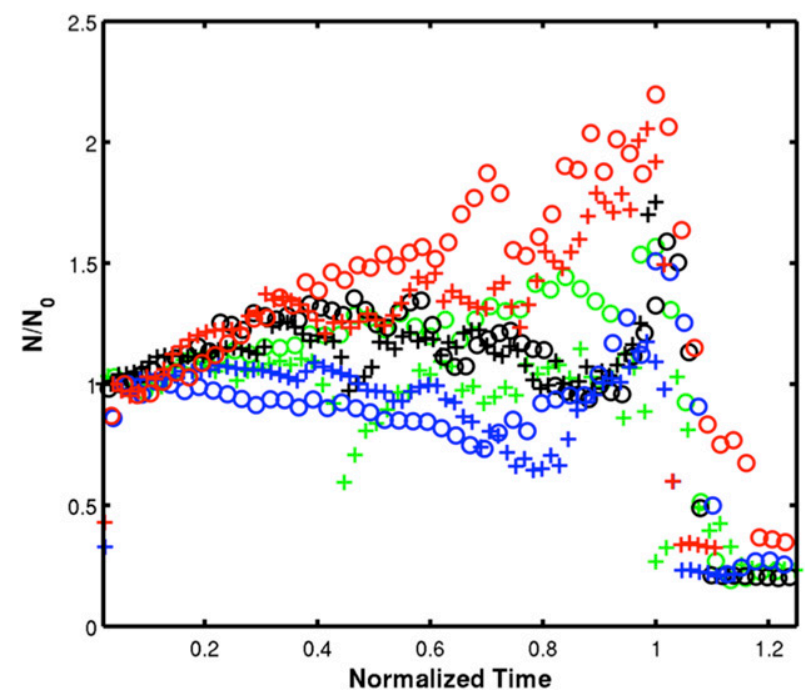

FIG. 11. Time evolution of the capping-layer Brunt-Väisälä frequency normalized by its initial value. Time has also been normalized such that the time of CAP removal corresponds to 1 . The circles represent the plain cases and the plus signs represent the mountain cases. Profiles are indicated by color: linear (red), multilayer (blue), capping layer (black), and shallow layer (green). 

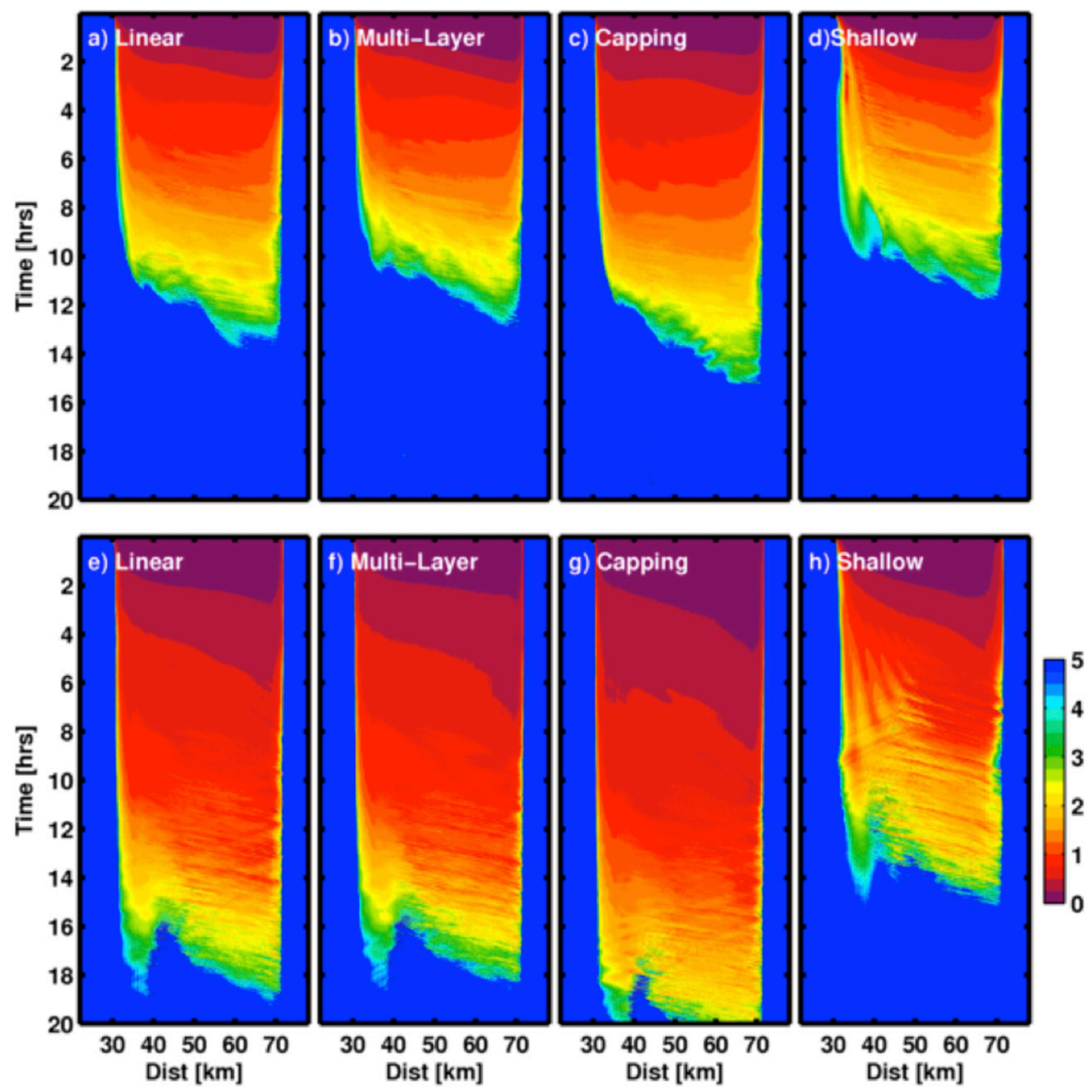

FIG. 12. Time-distance evolution of the column Froude number. (a)-(d) Mountain and (e)-(h) plain simulations. Profiles are labeled in the figure.

increasing Froude number. After $\mathrm{Fr} \sim 2$ the CAP is rapidly eroded, with complete removal corresponding to $\mathrm{Fr} \sim 3$. Beyond this point, the Froude number quickly becomes large as the buoyancy deficit (denominator) trends toward zero.

The dynamical significance of these Froude number transitions is highlighted by examination of the linearplain CAP (Fig. 13). The changes to the valley-mean potential temperature profile proceed similarly to the control case (Figs. 5 and 6 ) but can now be interpreted using Fr. The CAP top gradually lowers for the first $8 \mathrm{~h}$ of the simulation, corresponding to Fr increasing from 0 to 1 owing to the increased flow aloft. The gradual thinning of the CAP during that time is entirely due to spillover and no KHWs are present. Then, at Fr $\sim 1$ the lowering rate increases and negative interfacial heat fluxes associated with KHWs begin. The onset of the waves reduces the CAP more rapidly than the spillover alone, reflected as an accelerating increase in Fr. At Fr $\sim 2$ the column heat fluxes reach their maximum amplitude 

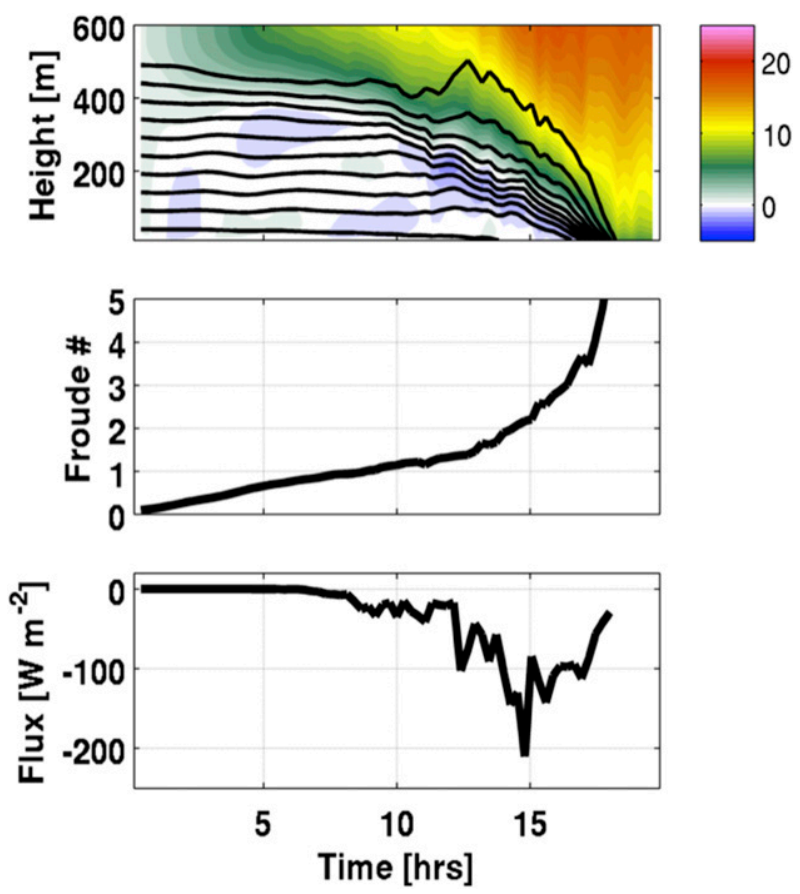

FIG. 13. Summary of the linear-plain case: (a) wind (shaded) and potential temperature (contoured), (b) Froude number time series, and (c) column minimum heat flux (negative downward).

(Fig. 13c) and the CAP top lowers even more sharply (Fig. 13a). By $\mathrm{Fr}=3$ the CAP is reduced to just a few tens of meters, and it is completely eradicated by $\mathrm{Fr}=4$. Figure 13 suggests that Fr not only reduces the parameter space by combining the effects of changes in wind shear and stability over time but also is closely related to the onset and amplification of turbulent mixing.

The relationship between turbulent heat flux and the Froude number is borne out across the remaining sensitivity cases (Fig. 14a). The wave-induced interfacial fluxes generally start at $\mathrm{Fr} \sim 1$, excepting the shallowplain simulation (green plus signs), which we discuss later. The flux amplitude continuously increases to a maximum proximal to $\mathrm{Fr}=2$, remains high for $\mathrm{Fr}$ between 2 and 3, then reduces toward zero for $\mathrm{Fr}>3$, corresponding to the complete removal of the stratification. This relationship also holds true for cases with steady winds aloft of different strengths, wherein cases with $\mathrm{Fr}<1$ correspond to steady-state CAPs whereas cases with $\mathrm{Fr}>1$ are erosive (simulations not shown).

Not surprisingly, Fr is also related to the gradient Richardson number evaluated at the CAP top (Fig. 14b). The $\mathrm{Fr}=1$ transition corresponds to $\mathrm{Ri}_{g}$ approaching its critical value, consistent with the onset of KHWs and turbulent heat flux. What is more surprising is that $\mathrm{Ri}_{g}$ is then roughly constant with increasing $\mathrm{Fr}$ despite a concurrent increase in magnitude of the heat fluxes, reflective of the mutual adjustment between shear and stratification demonstrated for the control case (Fig. 5). The value of $\mathrm{Ri}_{g}$ finally diminishes once the CAP is removed $(\mathrm{Fr}>3)$ and trends toward a subcritical Richardson number $\left[\log 10\left(\mathrm{Ri}_{c}\right)<-0.6\right]$ reflecting the transition to a well-mixed valley atmosphere.

Despite nearly constant values of $\mathrm{Ri}_{g}$ over the span of $\mathrm{Fr}=1-3$, the vertical scales of the KHWs vary, which is shown for each of three cases in Fig. 15. At Fr $=1.2$, the waves are diminutive and confined to the top edge of the CAP, whereas at $\mathrm{Fr}=2.2$ pronounced billows pervade the greater CAP depth. Thus, the minimum in heat flux at $\mathrm{Fr} \sim 2$ is associated with the transition to layer-deep KHWs. It is worth reemphasizing that $\mathrm{Fr}=2$ closely corresponds with $\mathrm{Ri}_{b}=0.25$ for the CAP layer, which is indicative of a bulk breakdown of the stratification and a transition to a more turbulent regime irrespective of locally evaluated gradients (Banta el al. 2003, 2006). That the CAP is not immediately destroyed at this threshold reflects the horizontal inhomogeneity within the valley. Internal circulations redistribute the cold air and offset the locally vigorous mixing. Thus, fluxes remain large beyond $\mathrm{Fr}=2$ until the source of cold air is entirely exhausted.

A related aspect of these results is that the magnitudes of the turbulent heat fluxes are also proportional to the strength of the underlying CAP (not shown). The cappinglayer cases experience the strongest heat fluxes, whereas the shallow cases are more subdued in their turbulent mixing. This result helps to explain the results presented in Figs. 9 and 10, which show that cold air is removed more rapidly from strong CAPs than from weaker CAPs. In total, this effect tends to converge the time scales for CAP removal across the range of stability profiles and makes the time to "mix out" more similar than might otherwise be expected.

Finally, we note that the shallow CAP cases have one distinct difference from deeper ones that is particularly evident in the shallow-plain case early in its simulation when the relationship between $\mathrm{Fr}$ and the onset of turbulent fluxes does not hold (green plus signs, Fig. 14a). Turbulent heating in that case begins at much smaller values of Fr because of strong eddies forming as the inflowing airstream separates from the leading edge of the valley (not shown). The resulting turbulence impinges on the CAP top, thereby inducing turbulent heat fluxes long before the mean flow above the CAP reaches a threshold to induce dynamic instability. Later, when KHWs begin to form, the erosion progresses more similarly to the other cases. Hence, nonlocal turbulence also plays a role in the breakup of the shallow cases. 

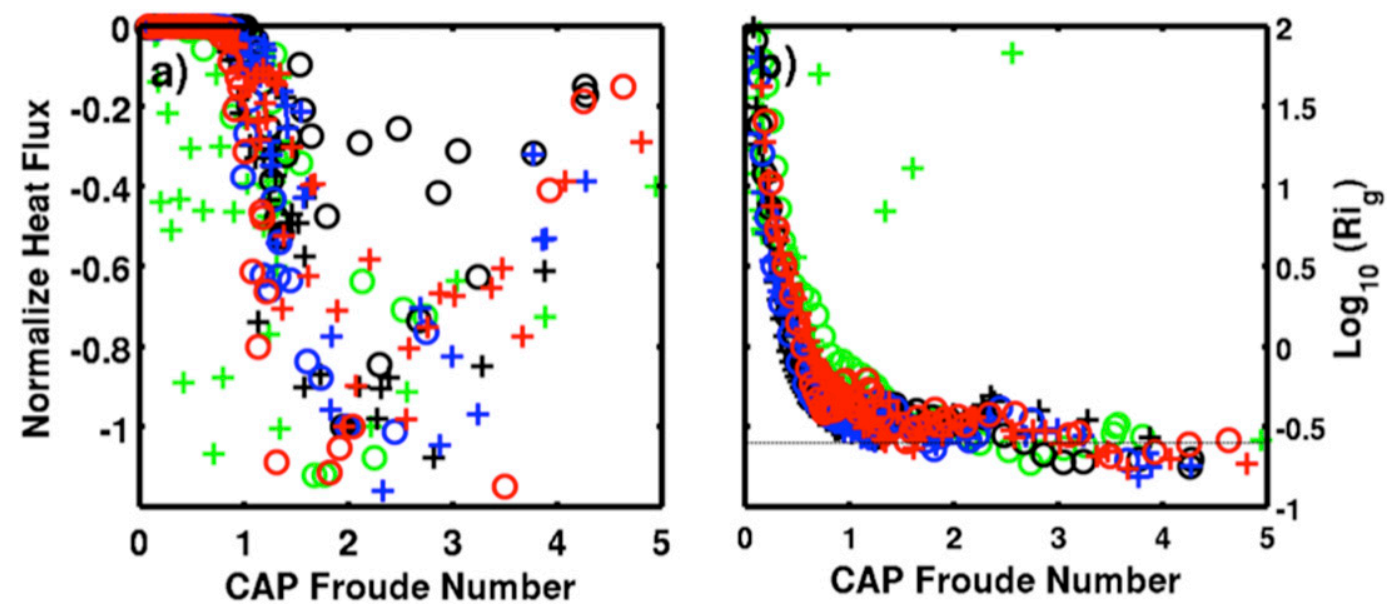

FIG. 14. Summary of the CAP parameter space: (a) column minimum heat flux vs Froude number for each case. (b) Log base 10 of the gradient Richardson number at the CAP top vs Froude number $\left[\log 10\left(\mathrm{Ri}_{c}\right)=-0.6\right]$. Circles represent the mountain cases and plus signs represent the plain cases. Colors correspond to the different profiles: linear (red), multilayer (blue), capping layer (black), and shallow layer (green).

\section{Comparison with observations}

The results of our control simulation compare favorably with observations of wind-induced CAP removal during PCAPS IOP-1 (Fig. 16). The potential temperature and wind data for IOP-1 are derived from numerous balloon soundings collocated with a radio acoustic sounding system and radar wind profiler in the center of the Salt Lake Valley. Further details are available in Lareau et al. (2013) and Lareau and Horel (2015). Despite the differences between our idealized simulations and PCAPS observations, both reveal CAPs thinning from initial depths of about $500 \mathrm{~m}$ down to the surface in about $15 \mathrm{~h}$ owing to interaction with accelerating wind aloft. Also, as the IOP-1 CAP thins from the top down, the static stability is increased, which is a key aspect of the control simulation. Even more striking is the similarity at the surface, where both observation and simulation show steplike jumps in temperature as the CAP is eroded to the ground. This signature is characteristic of mechanically removed CAPs, and similar temperature traces were recorded throughout the valley during IOP-1.

It is also encouraging that Fr represents the observed CAP evolution. For both the observations during IOP-1 and the control simulation, Fr varies slowly up until $\mathrm{Fr}=2$ and more rapidly as the stratification is reduced and warm air is mixed to the surface. There is a distinct increase in the reduction of the CAP during IOP-1 coincident with the $\mathrm{Fr}=2$ transition as seen earlier in Fig. 13.

The relationship between Fr and wave dynamics as determined from our simulations is also consistent with the observations. For example, aerosol backscatter from a vertically pointing laser ceilometer (Fig. 17) reveals that small waves propagate along the upper edge of the $\mathrm{CAP}$ at $\mathrm{Fr} \sim 1$, whereas those waves grow, becoming overturning billows that impact the depth of the aerosol

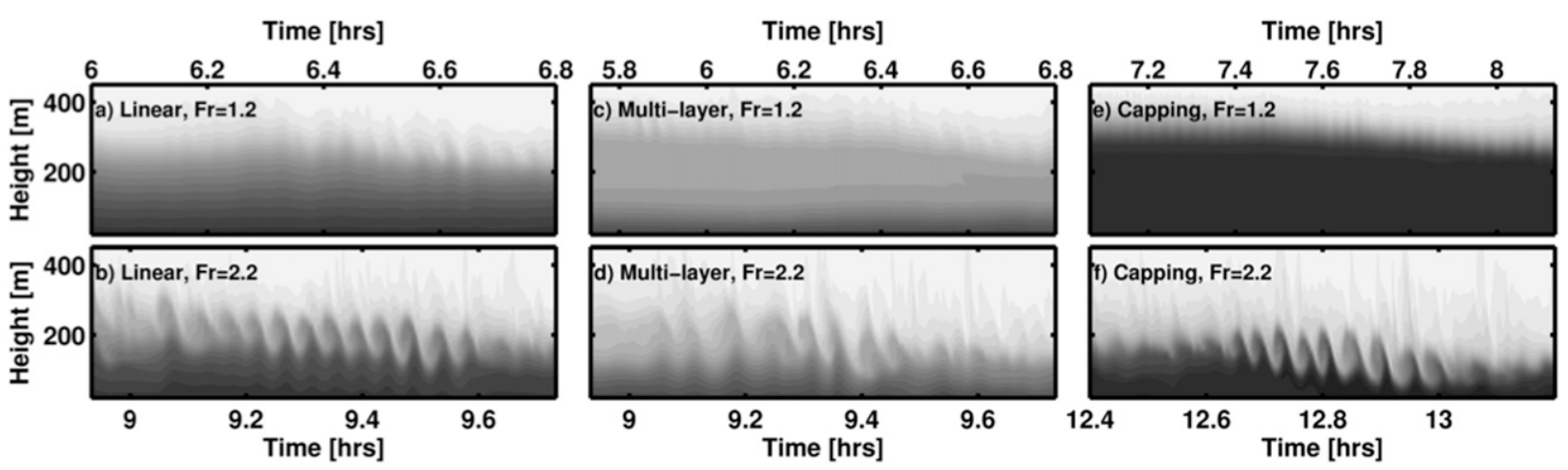

FIG. 15. Kelvin-Helmholtz waves at (a),(c),(e) Fr $\sim 1.2$ and (b),(d),(f) Fr $\sim 2.2$ for (a),(b) mountain linear, (c), (d) mountain multilayer, and (e),(f) mountain capping layer. 

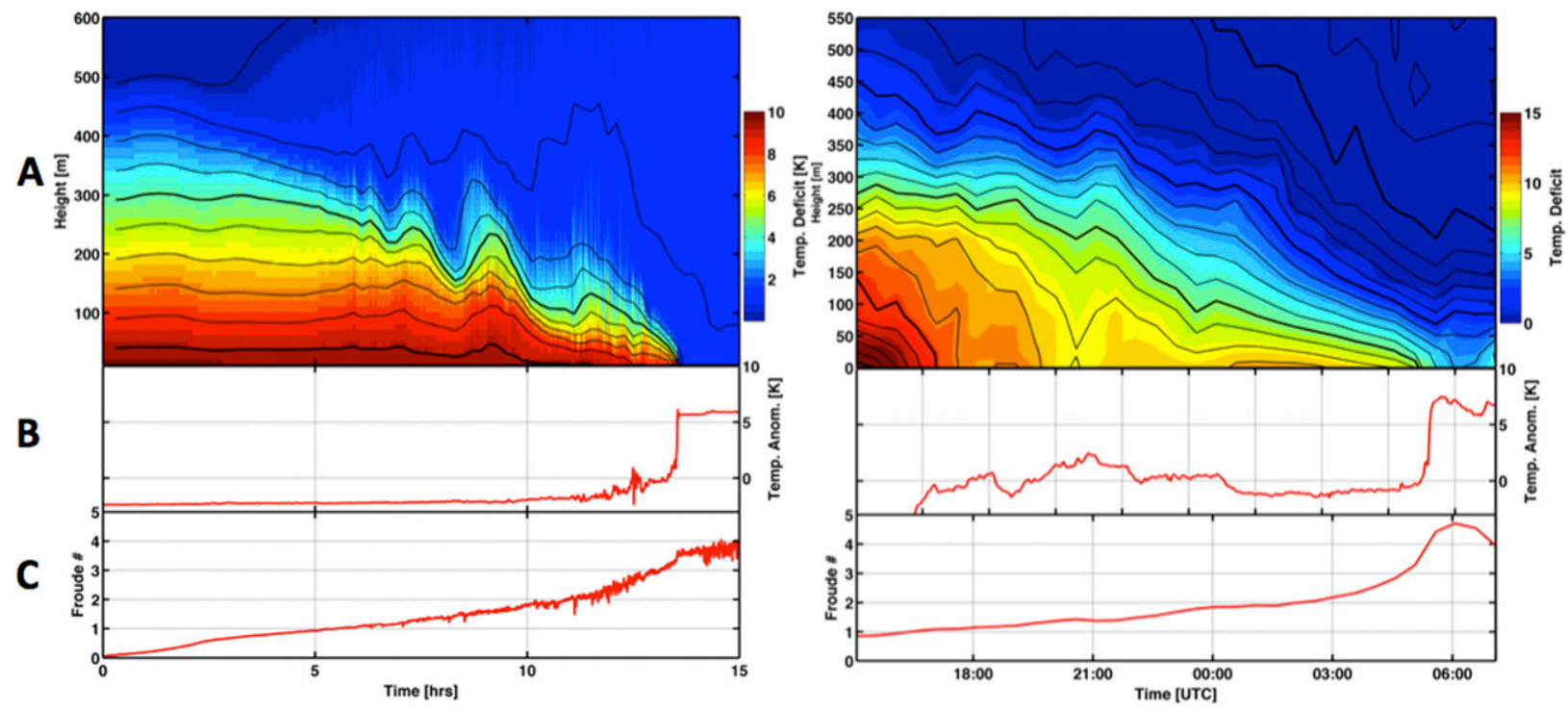

FIG. 16. Comparison between the (left) linear-mountain simulation and (right) PCAPS IOP-1 on 2-3 Dec 2010. (a) Time-height potential temperature and temperature deficit (shading). (b) Surface temperature. (c) CAP Froude number.

layer by $\mathrm{Fr}=2$. The observed KHWs when $\mathrm{Fr}=2$ have a period of about $3 \mathrm{~min}$, amplitude of $100-200 \mathrm{~m}$, and estimated wavelengths of about $1 \mathrm{~km}$, similar to the simulated KHWs (see Fig. 4). Moreover, the turbulent heat flux magnitudes during IOP-1 were recorded as the edge of the CAP passed over a 50-m tower equipped with a sonic anemometer. The maximum flux magnitudes were approximately $100-150 \mathrm{~W} \mathrm{~m}^{-2}$, closely matching the simulated values (not shown).

Beyond IOP-1, the Froude number also shows some promise for distinguishing between steady-state CAPs and those that experience appreciable or rapid erosion. For example, the CAP during IOP-9 (see a representative sounding for it in Fig. 1) was not eroded to the surface despite strong wind aloft. The Froude number for that sounding is about 1 and never exceeded that value despite a number of hours with strong winds. Only minor wave-induced perturbations and temporary thinning were observed. Had the winds aloft increased further, it is likely that the CAP would have been more substantively affected.

\section{Summary and conclusions}

In this study we have presented results using idealized numerical simulations to examine wind-induced CAP breakup. Two regimes for CAP removal are identified: 1) laminar spillover and 2) the interplay of turbulent mixing and warm-air advection. The spillover regime affects the CAP prior to the onset of dynamic instabilities and is due to the downward flux of momentum into the CAP. Provided sufficient momentum, the upper layers of the CAP are advected over the confining topography and out of the valley, thus reducing the CAP over time. The degree of spillover is sensitive to the specific terrain configuration and can be expected to vary greatly depending on local terrain features.

The second removal regime arises from turbulent entrainment of cold air into the flow aloft. As the flow continues to accelerate aloft, the vertical shear and stability mutually adjust along the top of the CAP to maintain a region of dynamic instability that leads to breaking KHWs. The turbulent mixing within the waves proceeds as a two-step process: first, the KHWs mix cold air vertically, then warmer inflow air replaces the partially mixed air above the CAP, which results in continual lowering of the CAP top over time. The removal of the cold air at the surface tends to occur as a sudden burst of warm air.

The onset and amplification of KHWs and their attendant fluxes are controlled by the CAP Froude number $(\mathrm{Fr})$, which is a bulk measure of the CAP strength relative to the flow aloft. When Fr exceeds unity, KHWs begin. KHWs subsequently increase in scale up to $\mathrm{Fr} \sim 2$, at which point breaking waves pervade the entire CAP depth, leading to stronger heat flux and more rapid CAP breakdown. That Fr distinguishes between erosive and steady-state conditions is potentially useful. For a given CAP profile (measured in situ with radiosondes or from ridge-valley temperature differences), forecasters can estimate the wind speed required for Fr to exceed 1 and, thus, for turbulent erosion to commence. If the winds are expected to reach strengths that would lead to $\mathrm{Fr}=2$, mixout should be expected to follow. 

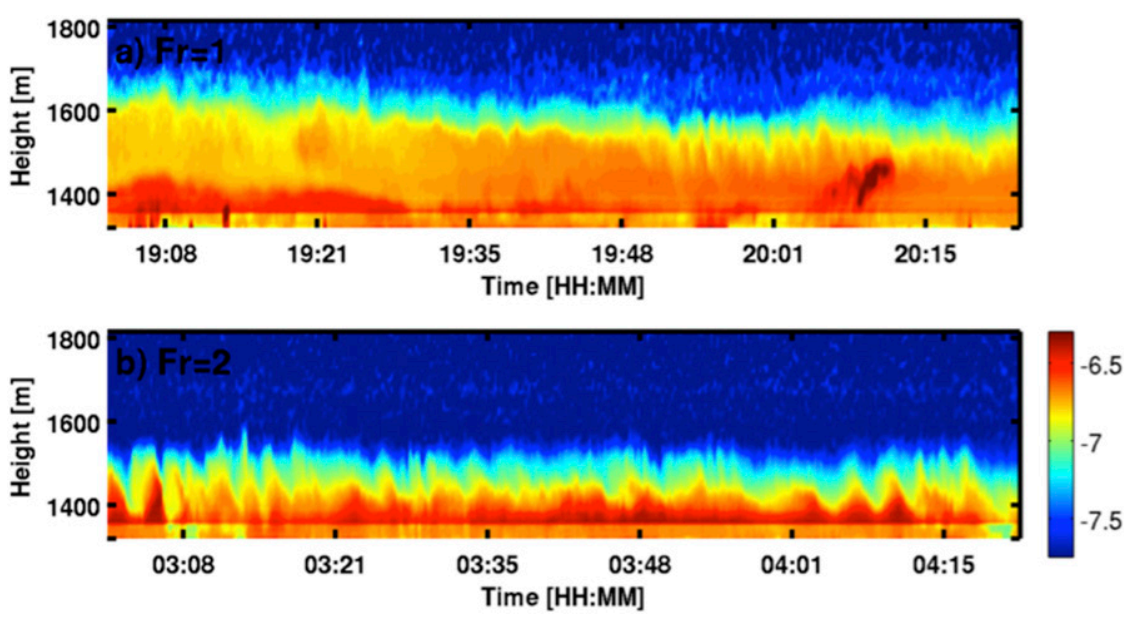

FIG. 17. Example of waves on 3 Dec during PCAPS IOP-1 for (a) $\mathrm{Fr}=1$ and (b) $\mathrm{Fr}=2$. Data are aerosol backscatter from a laser ceilometer.

However, more work is required to better understand the interplay of spillover and turbulence as well as the applicability of these results to basins of varying scale. Thus, some caution is necessary in the application of our results without a robust understanding of local and regional climatological CAP response to wind. Furthermore, other competing processes, such as radiative cooling or strong warm-air advection, may act to maintain stratification despite turbulent erosion.

Our model results indicate that mechanical removal of CAPs by wind is a viable mechanism to ventilate large mountain valleys on time scales of less than a day and, in some instances, less than $12 \mathrm{~h}$. This contrasts with the previous results of Zhong et al. (2001), who indicate that CAP removal by microscale turbulent erosion alone is too slow to remove a stratified air mass from a basin. One key difference in our findings is the link between CAP strength and the rate of removal, which converges the time scale for ventilation across a range of CAP strengths. Also, the bulk breakdown of the stratified layer was not considered in previous semianalytic models. While our results are broadly consistent with observed CAP removal in limited cases, in order to more thoroughly test our findings, additional observational studies are required. Such studies would need to more fully resolve turbulent fluxes of heat and momentum due to shear instability at the top of the CAP as well as quantify the degree of spillover from a basin. Future studies should also include more complete representation of the atmosphere by examining the interplay of exterior forcings (e.g., wind and radiation) and address a broader range of valley sizes and aspect ratios.

Acknowledgments. The manuscript was improved thanks to comments from C. David Whiteman, Courtenay Strong, and Erik Parkyjak. The support and resources from the Center for High Performance Computing at the University of Utah are gratefully acknowledged. Grant ATM-0938397 from the National Science Foundation supports this research.

\section{REFERENCES}

Banta, R. M., Y. L. Pichugina, and R. K. Newsom, 2003: Relationship between low-level jet properties and turbulence kinetic energy in the nocturnal stable boundary layer. J. Atmos. Sci., 60, 2549-2555, doi:10.1175/1520-0469(2003)060<2549:RBLJPA > 2.0.CO;2.

, — , and W. A. Brewer, 2006: Turbulent velocity-variance profiles in the stable boundary layer generated by a nocturnal low-level jet. J. Atmos. Sci., 63, 2700-2719, doi:10.1175/ JAS3776.1.

Beard, J. D., C. Beck, R. Graham, S. Packham, M. Traphagan, R. Giles, and J. G. Morgan, 2012: Winter temperature inversions and emergency department visits for Asthma in Salt Lake County, Utah, 2003-2008. Environ. Health Perspect., 120, 1385-1390, doi:10.1289/ehp.1104349.

Bell, R. C., and R. Thompson, 1980: Valley ventilation by cross winds. J. Fluid Mech., 96, 757-767, doi:10.1017/S0022112080002340.

Flamant, C., and Coauthors, 2006: Föhn/CAP interactions in the Rhine valley during MAP IOP 15. Quart. J. Roy. Meteor. Soc., 132, 3035-3058, doi:10.1256/qj.06.36.

Gillies, R. R., S.-Y. Wang, and M. R. Booth, 2010: Atmospheric scale interaction on wintertime Intermountain West low-level inversions. Wea. Forecasting, 25, 1196-1210, doi:10.1175/2010WAF2222380.1.

Grainger, C., and R. N. Meroney, 1993: Dispersion in an open-cut coal mine in stably stratified flow. Bound.-Layer Meteor., 63, 117-140, doi:10.1007/BF00705379.

Gubser, S., and H. Richner, 2001: Investigations into mechanisms leading to the removal of the cold-pool in Foehn situations. Extended Abstracts, MAP-Meeting, Bavaria, Germany, MAP, 4 pp. [Available online at http://www.map.meteoswiss.ch/ map-doc/NL15/gubser2.pdf.]

Kato, H., and O. M. Phillips, 1969: On the penetration of a turbulent layer into stratified fluid. J. Fluid Mech., 37, 643-665, doi:10.1017/S0022112069000784. 
Lareau, N. P., and J. D. Horel, 2015: Dynamically induced displacements of a persistent cold-air pool. Bound-Layer Meteor., 164, 291-316, doi:10.1007/s10546-014-9968-5.

—_, E. Crosman, C. D. Whiteman, J. D. Horel, S. W. Hoch, W. O. J. Brown, and T. W. Horst, 2013: The persistent cold-air pool study. Bull. Amer. Meteor. Soc., 94, 51-63, doi:10.1175/ BAMS-D-11-00255.1.

Lee, J. T., R. E. Lawson Jr., and G. L. Marsh, 1987: Flow visualization experiments on stably stratified flow over ridges and valleys. Meteor. Atmos. Phys., 37, 183-194, doi:10.1007/ BF01042440.

Lee, T. J., R. A. Pielke, R. C. Kessler, and J. Weaver, 1989: Influence of cold pools downstream of mountain barriers on downslope winds and flushing. Mon. Wea. Rev., 117, 2041-2058, doi:10.1175/1520-0493(1989)117<2041:IOCPDO>2.0.CO;2.

Malek, E., T. Davis, R. S. Martin, and P. J. Silva, 2006: Meteorological and environmental aspects of one of the worst national air pollution episodes in Logan, Cache Valley, Utah, USA. Atmos. Res., 79, 108-122, doi:10.1016/j.atmosres.2005.05.003.

Nappo, C. J., 2002: An Introduction to Atmospheric Gravity Waves. Academic Press, 279 pp.

Newsom, R. K., and R. M. Banta, 2003: Shear-flow instability in the stable nocturnal boundary layer as observed by Doppler lidar during CASES-99. J. Atmos. Sci., 60, 16-33, doi:10.1175/ 1520-0469(2003)060<0016:SFIITS $>2.0$.CO;2.

Pataki, D. E., B. J. Tyler, R. E. Peterson, A. P. Nair, W. J. Steenburgh, and E. R. Pardyjak, 2005: Can carbon dioxide be used as a tracer of urban atmospheric transport? J. Geophys. Res., 110, D15102, doi:10.1029/2004JD005723.

—, D. R. Bowling, J. R. Ehleringer, J. M. Zobitz, 2006: High resolution atmospheric monitoring of urban carbon dioxide sources. Geophys. Res. Lett., 33, L03813, doi:10.1029/2005GL024822.

Petkovšek, Z., 1992: Turbulent dissipation of cold air lake in a basin. Meteor. Atmos. Phys., 47, 237-245, doi:10.1007/BF01025620.

— lakes on the air pollution in them and on the irradiance above them. Meteor. Z., 3, 227-232.

Pollard, R. T., P. B. Rhines, and R. O. R. Y. Thompson, 1973: The deepening of the wind-mixed layer. Geophys. Fluid Dyn., 3, 381-404.

Pope, C. A., III, M. Ezzati, and D. W. Dockery, 2009: Fineparticulate air pollution and life expectancy in the United States. N. Engl. J. Med., 360, 376-386, doi:10.1056/NEJMsa0805646.

Price, J. F., C. N. K. Mooers, and J. C. Van Leer, 1978: Observation and simulation of storm-induced mixed-layer deepening. J. Phys. Oceanogr., 8, 582-599, doi:10.1175/ 1520-0485(1978)008<0582:OASOSI $>2.0 . \mathrm{CO} ; 2$.

Rakovec, J., J. Merše, S. Jernej, and B. Paradiž, 2002: Turbulent dissipation of the cold-air pool in a basin: Comparison of observed and simulated development. Meteor. Atmos. Phys., 79, 195-213, doi:10.1007/s007030200003.

Reddy, P. J., D. E. Barbarick, and R. D. Osterburg, 1995: Development of a statistical model for forecasting episodes of visibility degradation in the Denver metropolitan area. J. Appl. Meteor., 34, 616-625, doi:10.1175/1520-0450(1995)034<0616: DOASMF $>2.0 . \mathrm{CO} ; 2$.

Reeves, H. D., and D. J. Stensrud, 2009: Synoptic-scale flow and valley cold pool evolution in the western United States. Wea. Forecasting, 24, 1625-1643, doi:10.1175/2009WAF2222234.1.

Reinecke, P. A., and D. R. Durran, 2008: Estimating topographic blocking using a Froude number when the static stability is nonuniform. J. Atmos. Sci., 65, 1035-1048, doi:10.1175/ 2007JAS2100.1.
Schnell, R. C., S. J. Oltmans, R. R. Neely, M. S. Endres, J. V. Molenar, and A. B. White, 2009: Rapid photochemical production of ozone at high concentrations in a rural site during winter. Nat. Geosci., 2, 120-122, doi:10.1038/ngeo415.

Sheridan, P., and S. Vosper, 2014: Dependence of valley cold air pools on valley scale. 16th Conf. on Mountain Meteorology, San Diego, CA, Amer. Meteor. Soc., 15.2. [Available online at https://ams. confex.com/ams/16MountMet/webprogram/Paper251427.html.]

,$- \ldots$, and A. R. Brown, 2014: Characteristics of cold pools observed in narrow valleys and dependence on external conditions. Quart. J. Roy. Meteor. Soc., 140, 715-728, doi:10.1002/ qj.2159.

Silcox, G. D., K. E. Kelly, E. T. Crosman, C. D. Whiteman, and B. Allen, 2012: Wintertime $\mathbf{P M}_{2.5}$ concentrations in Utah's Salt Lake Valley during persistent, multiday cold-air pools. Atmos. Environ., 46, 17-24.

Skamarock, W. C., cited 2014: A standard test set for nonhydrostatic dynamical cores of NWP models: Density current test case. [Available online at http://www.mmm.ucar.edu/ projects/srnwp_tests/density/density.html.]

_- and Coauthors, 2008: A description of the Advanced Research WRF version 3. NCAR Tech. Note NCAR/TN-475+STR, 113 pp. [Available online at http://www.mmm.ucar.edu/wrf/users/ docs/arw_v3_bw.pdf.]

Soontiens, N., N. Stastna, and M. L. Waite, 2013: Numerical simulations of waves over large crater topography in the atmosphere. J. Atmos. Sci., 70, 1216-1232, doi:10.1175/JAS-D-12-0221.1.

Straka, J. M., R. B. Whilhelmson, L. J. Wicker, J. R. Andernson, and K. K. Droegemeier, 1993: Numerical solutions of a nonlinear density current: A benchmark solution and comparisons. Int. J. Numer. Methods Fluids, 17, 1-22, doi:10.1002/ fld. 1650170103.

Strang, E. J., and H. J. S. Fernando, 2001a: Entrainment and mixing in stratified shear flows. J. Fluid Mech., 428, 349-386, doi:10.1017/ S0022112000002706.

— and - 2001b: Vertical mixing and transports through a stratified shear layer. J. Phys. Oceanogr., 31, 2026-2048, doi:10.1175/1520-0485(2001)031<2026:VMATTA > 2.0.CO;2.

Sun, J., L. Mahrt, R. M. Banta, and Y. L. Pichugina, 2012: Turbulence regimes and turbulence intermittency in the stable boundary layer during CASES-99. J. Atmos. Sci., 69, 338-351, doi:10.1175/JAS-D-11-082.1.

Tampieri, F., and J. C. R. Hunt, 1985: Two-dimensional stratified fluid flow over valleys: Linear theory and laboratory investigation. Bound.-Layer Meteor., 32, 257-279, doi:10.1007/ BF00121882.

Vosper, S. B., and A. R. Brown, 2008: Numerical simulations of sheltering in valleys: The formation of night time cold-air pools. Bound.-Layer Meteor., 127, 429-448, doi:10.1007/ s10546-008-9272-3.

Vrhovec, T., and A. Hrabar, 1996: Numerical simulations of dissipation of dry temperature inversions in basins. Geofiz., 13, 81-96.

Whiteman, C. D., X. Bian, and S. Zhong, 1999: Wintertime evolution of the temperature inversion in the Colorado Plateau basin. J. Appl. Meteor., 38, 1103-1117, doi:10.1175/1520-0450(1999)038<1103: WEOTTI $>2.0 . \mathrm{CO} ; 2$.

, S. Zhong, W. J. Shaw, J. M. Hubbe, X. Bian, and J. Mittelstadt, 2001: Cold pools in the Columbia basin. Wea. Forecasting, 16, 432-447, doi:10.1175/1520-0434(2001)016<0432: CPITCB $>2.0 . \mathrm{CO} ; 2$.

Wolyn, P. G., and T. B. McKee, 1989: Deep stable layers in the intermountain western United States. Mon. Wea. Rev., 117, 461472, doi:10.1175/1520-0493(1989)117<0461:DSLITI>2.0.CO;2. 
Zängl, G., 2003: The impact of upstream blocking, drainage flow and the geostrophic pressure gradient on the persistence of cold-air pools. Quart. J. Roy. Meteor. Soc., 129, 117-137, doi:10.1256/qj.02.99.

2005: Winterime cold-air pools in the Bavarian Danube Valley basin: Data analysis and idealized numerical simulations. J. Appl. Meteor., 44, 1950-1971, doi:10.1175/JAM2321.1.

Zardi, D., and C. D. Whiteman, 2013: Diurnal mountain wind systems. Mountain Weather Research and Forecasting: Recent Progress and Current Challenges, F. K. Chow, S. F. J. De Wekker, and B. Snyder, Eds., Springer, 35-119.
Zhong, S., C. D. Whiteman, X. Bian, W. J. Shaw, and J. M. Hubbe, 2001: Meteorological processes affecting evolution of a wintertime cold air pool in a large basin. Mon. Wea. Rev., 129, 2600-2613, doi:10.1175/1520-0493(2001)129<2600:MPATEO >2.0.CO;2.

_, X. Bian, and C. D. Whiteman, 2003: Time scale for cold-air pool breakup by turbulent erosion. Meteor. Z., 12, 229-23, doi:10.1127/0941-2948/2003/0012-0231.

Zhou, B., and F. K. Chow, 2014: Nested large-eddy simulations of the intermittently turbulent stable atmospheric boundary layer over real terrain. J. Atmos. Sci., 71, 1021-1039, doi:10.1175/ JAS-D-13-0168.1. 